
\title{
$\angle S$ Research Square \\ Hub Genes and Key Pathway Identification in Wilms Tumor Based on Bioinformatics Analysis
}

\section{Basavaraj Vastrad}

Department of Biochemistry, Basaveshwar College of Pharmacy, Gadag, Karnataka 582103, India. https://orcid.org/0000-0003-2202-7637

\section{Chanabasayya Vastrad ( $\nabla$ channu.vastrad@gmail.com )}

Biostatistics and Bioinformatics, Chanabasava Nilaya, Bharthinagar, Dharwad 580001, Karanataka, India. https://orcid.org/0000-0003-3615-4450

\section{Iranna Kotturshetti}

Department of Ayurveda, Rajiv Gandhi Education Society`s Ayurvedic Medical College, Ron, Karnataka 562209, India. https://orcid.org/0000-0003-1988-7345

\section{Research Article}

Keywords: protein-protein interaction, gene expression, Wilms tumor, pathways, differentially expressed genes

Posted Date: December 22nd, 2020

DOI: https://doi.org/10.21203/rs.3.rs-133323/v1

License: (c) (1) This work is licensed under a Creative Commons Attribution 4.0 International License.

Read Full License 


\section{Abstract}

Wilms tumor (WT) is a childhood kidney cancer with unknown etiology. Gene expression analysis has become very essential in WT. Thus, we performed an integrated analysis of gene expression data to identify new molecular mechanisms and key functional genes in WT. Gene expression (GSE60850) dataset was downloaded from Gene Expression Omnibus. Differentially expressed genes (DEGs) were identified using limma. Pathway and Gene Ontology (GO) enrichment analyses were performed for the DEGs by ToppGene database. Then, protein-protein interaction (PPI) networks and modules were established by the Mentha database and PEWCC1, and visualized by Cytoscape software. Target gene miRNA regulatory network and target gene - TF regulatory network were established by the Network Analyst database and visualized by Cytoscape software. Finally, survival analysis, expression analysis, stage analysis, mutation analysis, immunohistochemical (IHC) analysis, receiver operating characteristic (ROC), reverse transcription polymerase chain reaction (RT-PCR) and immune infiltration analysis of hub genes was performed. We identified 988 DEGs ultimately including 502 up regulated genes and 486 down regulated genes. Pathway and GO enrichment analysis revealed that DEGs were mainly enriched in D-myo-inositol (3,4,5,6)-tetrakisphosphate biosynthesis, platelet activation, cholesterol biosynthesis III, and complement, coagulation cascades, embryo development, cell surface, DNA-binding transcription factor activity, carboxylic acid metabolic process, extracellular space and signaling receptor binding. FN1, AURKA, TRIM41, NFKBIA, TXNDC5, SIN3A, MAGI1, GPRASP2, UCHL1 and FXYD6 were filtrated as the hub genes. These identified DEGs and hub genes facilitate our knowledge of the underlying molecular mechanism of WT and have the potential to be used as diagnostic and prognostic biomarkers or therapeutic targets for WT.

\section{Introduction}

Wilms tumor (WT) is the rare diagnosed pediatric tumor worldwide and is named as nephroblastoma [1]. WT is form of kidney cancer that mostly advances in children under age under 10 years [2]. Because of routine early screening and recent advances in treatment techniques, long-term survival rates have upgraded [3]. However, in developing countries, most WT patients are diagnosed at an end stage, with poor prognosis [4]. Therefore, further studies should still be emphasized for the early diagnoses, prognosis and targeted therapy of WT.

Genetic aberrations and its related pathways have been reported to be significant factors contributing to the progression of WT. Genes such as IGF2 [5], WT1 [6], RASSF1A [7], PAF1 [8], and DROSHA and DICER1 [9] as well as signaling pathways such as WNT/ $\beta$-catenin pathway [10], IGF signaling pathway [11], S1P/S1P1 signaling pathway [12], PTEN/PI3K/AKT signaling pathway [13] and VEGF-C/VEGFR-2 signaling pathway [14] were responsible for pathogenesis of WT. Despite improvement and progress in WT diagnosis, prognosis and treatment, the underlying WT molecular mechanisms are not entirely clear 
and novel diagnosis, prognosis and treatment options are still needed for more effective control of WT development.

Gene expression profile analysis is a high-throughput method for detecting messenger RNA expression in various cancer tissues or cell samples. By analyzing the different gene expression between cancer patients and normal controls, an improved understanding of the molecular mechanism of a various tumors can be obtained, facilitating the identification of the potential key genes and pathways for diagnostics markers, prognostics markers and targeted therapy [15-16].

The current study aimed to explore the molecular pathogenesis of WT by a computational bioinformatics analysis of gene expression. Gene expression data from the Gene Expression Omnibus (GEO) database was extracted, and differentially expressed genes (DEGs) between WT and normal samples were identified. The possible functions of the DEGs were predicted using pathway and gene ontology (GO) enrichment analysis. Furthermore, protein-protein interaction (PPI) networks were constructed using mentha PPI database, and visualized and module analysis was conducted using Cytoscape software to search for essential hub genes that may be associated in the progression of WT. Dysregulation of microRNAs (miRNAs) and transcription factors (TFs) have been indicated to be associated with the pathogenesis of WT, the WT specific regulatory networks of target gene and miRNA, and target gene and TFs were constructed. Validation of the hub genes was performed to screen genes with prognostic and diagnostics significance in WT.

\section{Materials And Methods}

\section{Microarray data}

Human gene expression microarray data of WT samples $(n=36)$ and normal samples $(n=36)$ were obtained from the Gene Expression Omnibus (GEO, https://www.ncbi.nlm.nih.gov/geo/) with an accession ID of GSE60850. The platform of GSE60850 is GPL19130 Breakthrough Human 17K 2.1.2.

\section{Data preprocessing}

The raw data in GSE60850 were preprocessed using limma [17], an R software package and it implemented background correcting, quantile normalization and expression calculation automatically. Then, probe values were translated to gene-symbol values based on message associated in microarray platform, and probes without proper gene-symbols were excluded.

\section{Differentially Expressed Genes}

Based on the gene expression microarray data, DEGs between WT samples and normal samples were identified using limma [17], an R software package. The corresponding p-values were calculated using ttest provided by limma. The genes met the criteria of $p$-value $<0.05$ and $\mid \log 2$ fold change $(F C) \mid \geq 1.22$ for up regulated genes and $\mid \log 2$ fold change $(F C) \mid \geq-1.39$ for down regulated genes were defined as significant DEGs between the two groups. 


\section{Pathway enrichment analysis of DEGs}

BIOCYC (https://biocyc.org/) [18], Kyoto Encyclopedia of Genes and Genomes (KEGG; http://www.genome.jp/kegg/) [19], Pathway Interaction Database (PID, http://pid.nci.nih.gov/) [20], Reactome (https://reactome.org/PathwayBrowser/) [21], Molecular signatures database (MSigDB, http://software.broadinstitute.org/gsea/msigdb/) [22], GenMAPP (http://www.genmapp.org/) [23], Pathway Ontology (https://bioportal.bioontology.org/ontologies/PW) [24] and PantherDB (http://www.pantherdb.org/) [25] database are used to understand the high-level functions and utilities of the biological system. ToppGene (ToppFun) (https://toppgene.cchmc.org/enrichment.jsp) [26] is a comprehensive set of functional annotation tools for researchers to understand biological meaning behind large scale of genes. $P<0.05$ was set as the cut-off criterion.

\section{GO enrichment analysis of DEGs}

GO (http://www.geneontology.org/) [27] enrichment analysis is a universal genes analysis method, which can contribute functional classification for genomic data, including categories of BPs, cellular component (CC), and molecular function (MF). ToppGene (ToppFun) (https://toppgene.cchmc.org/enrichment.jsp) [26] is an online tool for gene functional classification, which can systematic and integrative analysis of large gene lists. In this study, to analyze the functions of DEGs, GO enrichment analysis were conducted using the ToppGene online tool; $p<0.05$ was set as the cutoff point.

\section{PPI network construction and module analysis}

Mentha (https://mentha.uniroma2.it/index.php) [28] was an online biological tool which had a major role in the analysis of biological information and integrates different PPI database such as IntAct (https://www.ebi.ac.uk/intact/) [29], MINT (https://mint.bio.uniroma2.it/) [30], BioGRID (https://thebiogrid.org/) [31], DIP (http://dip.doe-mbi.ucla.edu/dip/Main.cgi) [32] and MatrixDB (http://matrixdb.univ-lyon1.fr/) [33]. As a result, based on the STRING database, a protein-protein interaction (PPI) network of WT was built. PPIs of DEGs (up and down regulated genes) were selected with a combination score $>0.9$. Subsequently, the PPI network was input into Cytoscape (http://www.cytoscape.org/) (version: 3.7.2) [34]. Five topological methods (node degree, betweenness centrality, stress centrality, closeness centrality and clustering coefficient ) using to rank and evaluated hub genes using network analyzer [35-39] and modules analysis were taken using PEWCC1 of Cytoscape plugin [40].

\section{Construction of target gene - miRNA regulatory network}

The target genes - miRNA interactions were predicted with NetworkAnalyst (https://www.networkanalyst.ca/) [41], which involves two miRNA databases such as DIANA-TarBase (http://diana.imis.athena-innovation.gr/DianaTools/index.php?r=tarbase/index) [42] and miRTarBase (http://mirtarbase.mbc.nctu.edu.tw/php/download.php) [43]. Subsequently, the target genes - miRNA regulatory network was input into Cytoscape (version: 3.7.2) [34]. 
Experimentally-validated target genes and their TFs were screened in one TF database ChEA database (http://amp.pharm.mssm.edu/lib/chea.jsp) [44]. TFs that have a regulatory relationship with the target genes in the constructed network were identified. The NetworkAnalyst (https://www.networkanalyst.ca/) [41] online tool was used to predict TF-regulating genes in the network. Cytoscape (version: 3.7.2) [34], an open-source platform for visualizing complex networks, was used to visualize target genes - TF regulatory network.

\section{Validation of hub genes}

The survival probability study was implemented using Kaplan-Meier method to compare overall survival curves between high and low expression gene groups UALCAN (https://ualcan.path.uab.edu/index.html) online dataset [45], which is a user-friendly, interactive web resource for the analysis of cancer transcriptome data.. $\mathrm{P}<0.05$ was considered to indicate a statistically significant difference. The expression analysis and stage analysis of hub genes were analyzed using UALCAN online dataset [45]. The mutation frequencies of up and down hub genes were inquired in cBioportal online database (http://www.cbioportal.org/) [46]. In addition, up and down regulated hub genes were further validated for their prognostic values (immunohistochemical (IHC) analysis in normal and cancer tissue) using The Cancer Genome Atlas database (https://www.proteinatlas.org/) [47]. Receiver operating characteristic (ROC) analyses are generally used to check out the conduct of disease diagnosis and prognosis. The area under the curve (AUC) was used to demonstrate the accuracy of an individual gene for predicting recurrence using R package "pROC" [48]. Reverse transcription polymerase chain reaction (RT-PCR) was carried out for validation of up and down regulated hub genes. Total RNA was extracted from the WT tissue sample and normal kidney tissue samples using TRI Reagent ${ }^{\circledR}$ (Sigma, USA) according to the manufacturer's protocol. A RNA was reverse transcribed into cDNA using FastQuant RT kit (with gDNase; Tiangen Biotech Co., Ltd.), according to the manufacturer's protocol. The primer sequences (Genewiz, Inc.) used for RT-PCR are listed in Table 1. The mRNA expression levels of hub genes were measured by Real time-PCR using the QuantStudio 7 Flex real-time PCR system (Thermo Fisher Scientific, Waltham, MA, USA). The following reaction conditions were used for RT-PCR: Initial denaturation at $95^{\circ} \mathrm{C}$ for 3 min followed by 40 cycles of denaturation at $95^{\circ} \mathrm{C}$ for $10 \mathrm{sec}$ and annealing and elongation at $60^{\circ} \mathrm{C}$ for $30 \mathrm{sec}$. The relative expression levels of up and down regulated hub genes were determined using the $2^{-\Delta \Delta C t}$ method [49] and normalized to the internal reference gene, $\beta$-actin. Immune infiltration analysis was performed using the TIMER (https://cistrome.shinyapps.io/timer/) [50] is a RNA-Seq expression profiling database from The Cancer Genome Atlas (TCGA) portal for up and down regulated hub genes, which is used to check the immune infiltrates ( $B$ cells, CD4+ T cells, CD8+ T cells, neutrophils, macrophages, and dendritic cells) across WT.

\section{Results}


After data, including 36 WT samples and 36 normal samples, was downloaded from GEO database and preprocessed. The results before and after normalization are shown Fig. 1A and Fig. 1B. 988 DEGs, including 486 up genes and 502 down genes were identified using limma packages on the basis of the cut off criteria $(P<0.05$ and $\mid \log 2$ fold change $(F C) \mid>1.39$ for up regulated genes and |log2 fold change (FC) $\mid<-1.22$ for down regulated genes) in WT samples compared with normal samples (Table 1). The volcano plot showed the up regulated and down regulated genes in dataset GSE60850 is shown in Fig. 2. The details of up and down regulated gene expression heat map are shown in Fig. 3 and Fig. 4.

\section{Pathway enrichment analysis of DEGs}

Pathway enrichment analysis of the DEGs (up and down regulated genes) was performed using ToppGene. Pathways were identified for the up regulated genes, including the cholesterol biosynthesis III (via desmosterol), superpathway of methionine degradation, complement and coagulation cascades, ECM-receptor interaction, FOXA1 transcription factor network, direct p53 effectors, hemostasis, extracellular matrix organization, phenylalanine tyrosine and tryptophan biosynthesis, tyrosine metabolism, ensemble of genes encoding extracellular matrix and extracellular matrix-associated proteins, genes encoding enzymes and their regulators involved in the remodeling of the extracellular matrix, plasminogen activating cascade, blood coagulation, altered lipoprotein metabolic, gluconeogenesis pathway, phenylalanine and tyrosine metabolism. Similarly, pathways were identified for the up regulated genes including the D-myo-inositol (3,4,5,6)-tetrakisphosphate biosynthesis, 1D-myoinositol hexakisphosphate biosynthesis $V$ (from Ins(1,3,4)P3), platelet activation, protein digestion and absorption, endothelins, alpha-synucleinsignaling, extracellular matrix organization, degradation of the extracellular matrix, MAP kinase kinase activity, glycolysis, gluconeogenesis, ensemble of genes encoding extracellular matrix and extracellular matrix-associated proteins, ensemble of genes encoding core extracellular matrix including ECM glycoproteins, collagens and proteoglycans, Wnt signaling pathway, integrin signalling pathway, activinsignalin, parkinson disease, quinapril pathway and diltiazem pathway. The detailed results of pathway enrichment analysis for up and down regulated genes are presented in Table 2 and Table 3.

\section{GO enrichment analysis of DEGs}

All up and down regulated genes were uploaded to the ToppGene software to identify GO function. GO enrichment analysis results for up and down regulated genes are presented in Table 4 and Table 5. For biological processes (BP), the top GO terms of up and down regulated genes were significantly enriched in carboxylic acid metabolic process, oxoacid metabolic process, embryo development and animal organ morphogenesis, were included. For cell component (CC), top GO terms of up and down regulated genes were significantly enriched in cell surface, endoplasmic reticulum, neuron projection and neuron part. For molecular function (MF), the top GO terms of up and down regulated genes were significantly enriched in signaling receptor binding, identical protein binding, DNA-binding transcription factor activity and calcium ion binding. 
The Mentha PPI database was used to construct PPI networks. The PPI network of the up regulated genes is illustrated in Fig. 5 with 7649 nodes and 17236 edges. The topology analysis (higest node degree distribution, betweenness centrality, stress centrality, closeness centrality and lowest clustring coefficient) for up regulated genes showed that ESR1, FN1, AURKA, SMURF1, PDK1, NANOG, SLC25A5, NUDT21, KCNQ3, ADM, CEL, CXCL3 and GABRA5 were the hub genes (Table. 6) and statistical results in scatter plot for node degree distribution, betweenness centrality, stress centrality, closeness centrality and clustring coefficient are shown in Fig. 6A - 6E. These identified hug genes were enriched in neuron part, ECM-receptor interaction, metabolism of proteins, negative regulation of response to stimulus, carboxylic acid metabolic process, response to oxygen-containing compound, programmed cell death, identical protein binding, cell surface, signaling receptor binding, metabolic pathways, ensemble of genes encoding extracellular matrix and extracellular matrix-associated proteins, and regulation of response to stress. Similarly, PPI network of the down regulated genes is illustrated in Fig. 7 with 7691 nodes and 16050 edges. The topology analysis (higest node degree distribution, betweenness centrality, stress centrality, closeness centrality and lowest clustring coefficient) for down regulated genes showed that VCAM1, DDIT4L, TCF4, PLK1, RB1, MEOX2, SYK, PLXDC1, TCF7L2, MAPK10, MAGI1 and MRPL15 were the hub genes (Table. 6) and statistical results in scatter plot for node degree distribution, betweenness centrality, stress centrality, closeness centrality and clustring coefficient are shown in Fig. 8A - 8E. These identified hug genes were enriched in cell adhesion molecules (CAMs), regulation of Wnt-mediated beta catenin signaling and target gene transcription, FoxO family signaling, regulation of retinoblastoma protein, embryo development, animal organ morphogenesis, ensemble of genes encoding extracellular matrix and extracellular matrix-associated proteins, pathways in cancer, innate immune system and ATP binding.

Based on the hub genes (up and down regulated) from the PPI module, pathway and GO terms for further analysis. We chose the four most significant modules (up regulated genes) for further analysis (Fig.9). Module 14 consisted of 174 nodes and 311 edges, module 24 consisted of 131 nodes and 144 edges, module 39 consisted of 113 nodes and 111 edges, and module 40 consisted of 97 nodes and 99 edges. Hub genes in these PPI modules were mainly enriched in the ECM-receptor interaction, metabolism of proteins, negative regulation of response to stimulus, programmed cell death, response to endogenous stimulus, neuron part, protein-containing complex binding, focal adhesion, proteoglycans in cancer, regulation of cell differentiation, signaling receptor binding, enzyme regulator activity, carboxylic acid metabolic process, regulation of response to stress, metabolism of amino acids and derivatives, metabolism of lipids and lipoproteins, cell motility and enzyme binding. Finally, we chose the four most significant modules (down regulated genes) for further analysis (Fig.10). Module 17 consisted of 145 nodes and 186 edges, module 24 consisted of 122 nodes and 188 edges, module 34 consisted of 100 nodes and 117 edges, and module 40 consisted of 93 nodes and 95 edges. Hub genes in these PPI modules were mainly enriched in the pathways including DNA-binding transcription factor activity, transcription regulatory region DNA binding, sequence-specific DNA binding, pathways in cancer, extracellular matrix organization, hemostasis, innate immune system, PDGFR-beta signaling pathway, cytokine signaling in immune system, signaling receptor binding, molecular function regulator, Wnt 
signaling pathway, embryo development, neurogenesis, regulation of cell differentiation, positive regulation of multicellular organismal process and cell surface.

\section{Construction of target gene - miRNA regulatory network}

Based on the interaction information of target genes and miRNAs in corresponding miRNA databases, the integrated regulatory network of target genes (up and down regulated) and relevant miRNAs were constructed (Fig. 11 and Fig. 12). We found that up regulated target genes such as CCND1 can be targeted by 197 miRNAs (ex, hsa-mir-2392), SCD can be targeted by 167 miRNAs (ex, hsa-mir-1269a), PTP4A1 can be targeted by 132 miRNAs (ex, hsa-mir-6731-5p), LDLR can be targeted by 123 miRNAs (ex, hsa-mir-4295) and RRM2 can be targeted by 102 miRNAs (ex, hsa-mir-4458) are listed in Table 7. These identified target genes were enriched in focal adhesion, PPAR signaling pathway, cell motility, organic substance catabolic process and superpathway of purine nucleotide salvage. Similarly, we found that down regulated target genes such as ZNF703 can be targeted by 115 miRNAs (ex, hsa-mir-3938), ENPP5 can be targeted by 114 miRNAs (ex, hsa-mir-4768-3p), MYLIP can be targeted by 113 miRNAs (ex, hsa-mir-552-5p), ENAH can be targeted by 92 miRNAs (ex, hsa-mir-4282) and ZBTB20 can be targeted by 85 miRNAs (ex, hsa-mir-4282) are listed in Table 7. These identified target genes were enriched in regulation of multicellular organismal development, integral component of plasma membrane, adaptive immune system, axon guidance and positive regulation of multicellular organismal process.

\section{Construction of target gene - TF regulatory network}

Based on the interaction information of target genes and TFs in corresponding TF database, the integrated regulatory network of target genes (up and down regulated) and relevant TFs were constructed (Fig. 13 and Fig. 14). We found that up regulated target genes such as MAGEC2 can be targeted by 207 TFs (ex, SOX2), TSPAN7 can be targeted by 173 TFs (ex, MYC), ESR1 can be targeted by 172 TFs (ex, HNF4A), PCSK6 can be targeted by 166 TFs (ex, EGR1) and LDLR can be targeted by 145 TFs (ex, TP63) are listed in Table 8. These identified target genes were enriched in organic substance catabolic process, intrinsic component of plasma membrane, neuron part, golgi apparatus and identical protein binding.Similarly, we found that down regulated target genes such as PLEKHO1 can be targeted by 184 TFs (ex, SOX2), CACHD1 can be targeted by 151 TFs (ex, AR), CASD1 can be targeted by 139 TFs (ex, NANOG), GLIS3 can be targeted by 132 TFs (ex, STAT3) and AFF3 can be targeted by 130 TFs (ex, TP53) are listed in Table 8. These identified target genes were enriched in cell projection part, regulation of transcription by RNA polymerase II and DNA-binding transcription factor activity.

\section{Validation of hub genes}

Te overall survival rates of patients with high expression of UCHL1, FN1, AURKA, TRIM41 and TXNDC5 were all significantly lower than those of patients with low/medium expression (Fig. 15), while overall survival rates of patients with low expression of SIN3A, MAGI1, GPRASP2, FXYD6 and NFKBIA were all significantly lower than those of patients with high expression (Fig. 16). The box plots (expression analysis) showed that the expression levels of FN1, AURKA, TRIM41, NFKBIA and TXNDC5 were 
significantly higher in primary tumor than those in the normal kidney for WT patients from TCGA (Fig. 17A -17E), while the expression levels of SIN3A, MAGI1, GPRASP2, UCHL1 and FXYD6 were significantly lower in primary tumor than those in the normal kidney for WT patients from TCGA (Fig. 17F -17J). The box plot suggested (stage analysis) that the high expression level of FN1, AURKA, TRIM41, NFKBIA and TXNDC5 show significant distance in different pathological stages in KT compared to normal (Fig. 18A $-18 \mathrm{E}$ ), while low expression level of SIN3A, MAGI1, GPRASP2, UCHL1 and FXYD6 show significant distance in different pathological stages in KT compared to normal (Fig. 18F -18J). Up and down regulated hub genes' alteration statuses in TCGA WT patients were analyzed using the CbioPortal database. FN1 altered (2\%), and missense mutation, truncating mutation, amplification and deep dilation were the main type. AURKA altered ( $0 \%)$. TRIM41 altered (8\%), and missense mutation and amplification were the main type. NFKBIA altered (0.3\%), and amplification was the main type. TXNDC5 altered (0.7\%), and missense mutation and truncating mutation were the main type. SIN3A altered (0.3\%), and missense mutation was the main type. MAGI1 altered (2.8\%), and inframe mutation, amplification and deep dilation was the main type. GPRASP2 altered (2\%), and truncating mutation and amplification were the main type. UCHL1 altered (0\%). FXYD6 altered (0.3\%), and amplification was the main type. The frequencies of alteration of each hub gene are shown in Fig. 19. The Human Protein Atlas database, which indicated the expression level of FN1, AURKA, TRIM41, NFKBIA and TXNDC5 were higher in WT tissue compared to normal kidney tissues (Fig. 20A-20E), while expression level of SIN3A, MAGI1, GPRASP2, UCHL1 and FXYD6 were lower in WT tissue compared to normal kidney tissues (Fig. 20F-20J). The ROC curve defined an optimal threshold to predict the recurrence risk of WT, and the AUC values of the ROC for FN1, AURKA, TRIM41, NFKBIA, TXNDC5, SIN3A, MAGI1, GPRASP2, UCHL1 and FXYD6 were $0.991,0.998,0.952,0.939,0.994,0.954,0.905,0.947,0.938$ and 0.973 , respectively (Fig. 21). RT-PCR result were consistent with the results of the database analysis, mRNA expression level of FN1, AURKA, TRIM41, NFKBIA and TXNDC5 were significantly higher in WT tissues compared with normal kidney tissues (Fig. 22A - 22E), while mRNA expression level of SIN3A, MAGI1, GPRASP2, UCHL1 and FXYD6 were significantly lower in WT tissues compared with normal kidney tissues (Fig. 22F - 22J). The Immune infiltration analysis of up and down hub genes from the TIMER was investigated using TCGA database. The results demonstrated that the higher expression level of FN1, AURKA, TRIM41, NFKBIA and TXNDC5 were all negatively associated with tumor purity (Fig. 23A - 23E), while lower expression level of SIN3A, MAGI1, GPRASP2, UCHL1 and FXYD6 positively associated with tumor purity (Fig. 23F - 23J).

\section{Discussion}

To better uncover the molecular pathogenesis and develop new prognostic, diagnostics and therapeutic strategies for WT, we performed this integrated analysis between WT patients and normal controls. A total of 988 genes across the studies were consistently differentially expressed in WT (502 up regulated and 486 down regulated) with FDR < 0.05. MEIS1 was identified with development of WT [51]. GUCY1A3 was linked with angiogenesis in glioma [52], but this gene may be involved in angiogenesis in WT. TFF1 was linked with progression of gastric cancer [53], but this gene may be involved in pathogenesis of WT. Elevated expression of genes such as FGG (fibrinogen gamma chain) [54] and CGA (glycoprotein 
hormones, alpha polypeptide) [55] were liable for advancement of hepatocellular carcinoma, but high expression of these genes may be associated with pathogenesis of WT. Methylation inactivation of tumor suppressor genes such as HOXA11 [56] and MAPK10 [57] were associated with development of various cancers types, but loss of these genes may be liable for progression of WT. Genes such as COL3A1 [58], S100P [59] and MY01B [60] were important for invasion of various cancer cells types, but these genes may be linked with invasion of WT cells.

In pathway enrichment analysis for up regulated genes were carried out.. High expression of enriched genes such as SERPINA1 [61], FGB (fibrinogen beta chain) [62], SCG3 [63], ITIH3 [64], FST (follistatin) [65], AMBP (alpha-1-microglobulin/bikunin precursor) [66], IGFBP1 [67], IGFBP6 [68] and PLOD3 [69] were responsible for advancement of various cancers types, but over expression of these genes may linked with pathogenesis of WT. Enriched genes such as CLU (clusterin) [70], VTN (vitronectin) [71], SERPINE1 [72], SERPINE2 [73], FN1 [74], SLC3A2 [75], ITGA2 [76], ITGA3 [77], ITGA5 [78], DOCK2 [79], L1CAM [80], CAV1 [81], TSPAN7 [82], CRLF1 [83], SRPX (sushi-repeat-containing protein, X-linked) [84], FGL1 [85], CCL20 [86], COL1A2 [87], SEMA3C [88], GDF15 [89], ANXA11 [90], SPP1 [91], LAMA1 [92], TDGF1 [93], CXCL3 [94], LGALS3 [95], SERPINB1 [96] and LUM (lumican) [97] were associated with invasion of various cancer cells types, but these genes may be liable for invasion of WT cells. Enriched genes such as SERPINA5 [98], ENO2 [99] and CSTB (cystatin B (stefin B)) [100] were involved in development of various cancers types, but these genes may be responsible for advancement of WT. Alteration in genes such as ESR1 [101], FOXA1 [102] and PRSS1 [103] were important for development of various cancer types, but mutation in these genes may be liable for progression of WT. Enriched genes such as NKX3-1 [104], GATA2 [105], CEACAM1 [106], RAB27B [107], SCUBE2 [108] and THBS2 [109] were involved in advancement of various cancers types, but these genes may be responsible for progression of WT. Enriched polymorphic genes such as MMP1 [110], APOA1 [111], ITPR3 [112], MMP3 [110], IGFBP3 [113], CSH1 [114], SERPINA6 [115] and APOC2 [116] were associated with pathogenesis of various cancers types, but these polymorphic genes may be linked with development of WT. Enriched genes such as VEGFC (vascular endothelial growth factor C) [117], GATA3 [118], CD44 [119] and S100A4 [120] were important for development of WT. Our study found that FDFT1, EBP (emopamil binding protein (sterol isomerase)), DHCR7, F5 (coagulation factor V (proaccelerin, labile factor)), SERPINC1, C4A, C4BPB, APOB (apolipoprotein B (including $\mathrm{Ag}(\mathrm{x})$ antigen)), PDE2A, DGKZ (diacylglycerol kinase, zeta 104kDa), APOH (apolipoprotein H (beta-2-glycoprotein I)), LRP8, HBE1, HBG1, GOT1, PAH (phenylalanine hydroxylase), FSTL3, AREG (amphiregulin (schwannoma-derived growth factor), ITIH2, $\mathrm{COCH}$ (coagulation factor C homolog, cochlin (limulus polyphemus)), CLEC2B, HGD (homogentisate 1,2-dioxygenase (homogentisate oxidase)) and YARS (tyrosyl-tRNAsynthetase) are up regulated in WT and has potential as a novel diagnostic and prognostic biomarker, and therapeutic target. In pathway enrichment analysis for down regulated genes were carried out. FCER1G was associated with chronic inflammation in kidney cancer [121], but this gene may be important for pathogenesis of WT. Enriched genes such as COL1A1 [122] STIM1 [123], MFAP2 [124], EFEMP1 [125], MMP11 [126], VCAM1 [127], COL2A1 [128], COL4A2 [129], COL13A1 [130], FMOD (fibromodulin) [131], ITGA8 [132], CAPN6 [133], MGP (matrix Gla protein) [134], SPON1 [135], FGF7 [136], PLXNA2 [137], CXCL12 [138], PTN (pleiotrophin (heparin binding growth factor 
8, neurite growth-promoting factor 1)) [139], FNDC1 [140], SERPING1 [141], PCSK6 [142], TCF7L2 [143] and TLE4 [144] were associated with invasion of various cancer cells types, but these genes may be liable for invasion of WT cells. Methylation inactivation of enriched tumor suppressor genes such as ADCY4 [145], FBLN1 [146], FBN2 [147], ADAMTS9 [148], NELL2 [149] and PCDH18 [150] were important for progression of various cancers such as breast cancer, colorectal cancer, nasopharyngeal cancer and kidney cancer, but loss of these genes may be linked with development of WT. Enriched genes such as VWF (Von Willebrand factor) [151] and ACVR2B [152] were identified with progression of WT. ITPR1 was linked with activation of autophagy in kidney cancer [153], but this gene may be responsible for induction of autophagy in WT. SYK (spleen tyrosine kinase) was liable for cancer drug resistance in ovarian cancer [154], but this gene may be involved in chemo resistance in WT. Enriched polymorphic genes such as MMP7 [155] and C1QA [156] were answerable for progression of various cancer types, but these polymorphic genes may be important for advancement of WT. Enriched genes such as S100A9 [157], SCUBE3 [158], PDGFC (platelet derived growth factor C) [159] and CTBP2 [160] were linked with development of various cancer types, but elevated expression of these genes may be responsible for progression of WT. Low expression of genes such as SPARCL1 [161], SEMA3F [162], PCDH9 [163], CDH11 [164] and NR3C2 [165] were liable for development various cancer types, but decrease expression of these genes may be associated with advancement of WT. PLXDC1 was identified with angiogenesis in ovarian cancer [166], but this gene may be associated with angiogenesis in WT. Our study found that ITPK1, ADCY2, MYLK (myosin, light polypeptide kinase), EDNRA (endothelin receptor type A), COL14A1, FBN3, ASPN (asporin (LRR class 1)), NCAM1, KLKB1, TLL1, F13A1, FGF14, C1QTNF7, PAPPA2, FRAS1, CILP (cartilage intermediate layer protein, nucleotide pyrophosphohydrolase), NRG3, FREM1, FGL2, BMPER (BMP binding endothelial regulator), RSPO3, PLXDC2, TNFSF8, DCHS1, MYCN (Vmycmyelocytomatosis viral related oncogene, neuroblastoma derived (avian)), PCDHB14, CDH5, ACVR2A, KCNJ8 and ABCC9 are down regulated in WT and has potential as a novel diagnostic and prognostic biomarker, and therapeutic target.

GO enrichment analysis for up regulated genes were carried out. High expression of enriched genes such as PDK1 [167], GCLM (glutamate-cysteine ligase, modifier subunit) [168], SPHK1 [169], NQ01 [170], CBS (cystathionine-beta-synthase) [171], P4HB [172], PCK2 [173], ADA (adenosine deaminase) [174], ADM (adrenomedullin) [175], AGR2 [176], ULBP2 [177], PTPRZ1 [178], LDLR (low density lipoprotein receptor (familial hypercholesterolemia)) [179], CASK (calcium/calmodulin-dependent serine protein kinase (MAGUK family)) [180], KRT17 [181], TRAP1 [182] and EMP2 [183] were liable for progression of various cancer types, but increase expression of these genes may be important for pathogenesis of WT. Enriched genes such as ACSL4 [184], TYRP1 [185], PPA1 [186], PSMB8 [187], STAT5B [188], ENPP1 [189], CLIC1 [190], STC2 [191], BCHE (butyrylcholinesterase) [192], APOM (apolipoprotein M) [193], HMGA1 [194], ICAM3 [195], DNER (delta-notch-like EGF repeat-containing transmembrane) [196] and CAV2 [197] were linked with invasion of various cancer cells types, but these genes may be liable for invasion of WT cells. Enriched genes such as FBP1 [198], INSIG1 [199], IER3 [200], GLDC (glycine dehydrogenase (decarboxylating)) [201], KYNU (kynureninase (L-kynurenine hydrolase)) [202], PLA2G2A [203], DKK1 [204], AZGP1 [205], WFDC1 [206] and SOCS2 [207] were answerable for pathogenesis of various cancer 
types, but low expression of these genes may be associated with development of WT. Enriched polymorphic genes such as COMT (catechol-O-methyltransferase) [208], PTGS2 [209], UTS2 [210], TMBIM1 [211], TAP2 [212] and EFNA1 [213] were culpable for progression of various cancer types, but these polymorphic genes may be linked with development of WT. Enriched genes such as SLC27A2 [214] and KRT10 [215] were important for drug resistance in ovarian cancer, but these genes may be liable for chemo resistance in WT. Methylation inactivation of tumor suppressor CDH13 was associated with progression of breast cancer [216], but inactivation of this gene may be important for advancement of WT. Our study found that CDH13, CEL (carboxyl ester lipase (bile salt-stimulated lipase)), MAT1A, ETFB (electron-transfer-flavoprotein, beta polypeptide), TYR (tyrosinase (oculocutaneous albinism IA)), MID1IP1, SCD (stearoyl-CoA desaturase (delta-9-desaturase)), PYCR2, PLP1, WARS (tryptophanyltRNAsynthetase), ER01A, SLC7A2, DECR2, ALDH4A1, CTPS1, GALE (UDP-galactose-4-epimerase), CYP8B1, DCT (dopachrometautomerase (dopachrome delta-isomerase, tyrosine-related protein 2)), PSMD6, RGN (regucalcin (senescence marker protein-30)), OTC (ornithine carbamoyltransferase), MECR (mitochondrial trans-2-enoyl-CoA reductase), EHHADH (enoyl-Coenzyme A, hydratase/3-hydroxyacyl Coenzyme A dehydrogenase), UGT2A3, PCCB (propionyl coenzyme A carboxylase, beta polypeptide), NRN1, HIST1H2BG, HIST1H2BK, NLGN1, HAMP (hepcidin antimicrobial peptide), KLHL17, HIST1H2BJ, LCP1, KLRK1, IL1RAP, GABRA5, BCAS3, CD3G and TSPAN4 are up regulated in WT and has potential as a novel diagnostic and prognostic biomarker, and therapeutic target. Similarly, GO enrichment analysis for down regulated genes was carried out. Enriched genes such as MEOX2 [217], SIX1 [218] and RARA (retinoic acid receptor, alpha) [219] were identified with development of WT. Methylation inactivation of enriched tumor suppressor genes such as HOXA5 [220], SALL2 [221], TCF21 [222], PAX1 [223], ZNF516 [224], EBF3 [225] and ZNF677 [226] were liable for advancement of various cancer types, but loss of these genes may be important for pathogenesis of WT. Low expression of enriched genes such as HOXB6 [227], TSHZ3 [228], SIN3A [229], CAMTA1 [230], TCF4 [231] and MEIS2 [232] were linked with progression of various cancer types, but decrease expression of these genes may be responsible for advancement of WT. Enriched genes such as HOXC10 [233], RECK (reversion-inducing-cysteine-rich protein with kazal motifs) [234], NRP1 [235], STOX2 [236], NR2F2 [237], GPR161 [238], PBX1 [239], KLF7 [240], TCF12 [241], TFAP4 [242], KLF12 [243] and ZBTB20 [244] were linked with invasion of various cancer cells types, but these genes may be responsible for invasion of WT cells. Enriched genes such as FGFR2 [245], RARB (retinoic acid receptor, beta) [246], EFNB1 [247], ABCG1 [248], AUTS2 [249], MLLT11 [250], GLIS3 [251], HIF3A [252], ELF1 [253], STAG1 [254], BCL11A [255] and TSC22D1 [256] were important for pathogenesis of various cancer types, but these genes may be linked with progression of WT. CNOT2 was linked with angiogenesis in breast cancer [257], but this gene may be associated with angiogenesis in WT. AFF3 was important for drug resistance in breast cancer [258], but this gene may be involved with chemo resistance in WT. Our study found that PDGFRB (platelet-derived growth factor receptor, beta polypeptide), KIDINS220, CLIC5, PGAP1, FLRT3, SLC8A1, ENAH (enabled homolog (Drosophila)), SMO (smoothened homolog (Drosophila)), STOX1, NRK (nik related kinase), MAFB (V-mafmusculoaponeuroticfibrosarcoma oncogene homolog B (avian)), RB1, NR2F1, MED25, ZNF211, ZNF605, ZNF420, ZNF135, ZNF300, ZNF501 and ZNF532 are down regulated in WT and has potential as a novel diagnostic and prognostic biomarker, and therapeutic target. 
PPI network was constructed and analyzed for up regulated genes. AURKA was important for pathogenesis WT [259]. SMURF1 was responsible for invasion of breast cancer cells [260], but this gene may be liable for invasion of WT cells. NUDT21 was involved in proliferation of glioblastoma cells [261], but this gene may be associated with proliferation WT cells. Our study found that NANOG (nanoghomeobox), SLC25A5 and KCNQ3 are up regulated in WT and has potential as a novel diagnostic and prognostic biomarker, and therapeutic target. Similarly, PPI network was constructed and analyzed for down regulated genes. PLK1 was associated with proliferation of kidney cancer cells [262], but this gene may be liable for proliferation of WT cells. Low expression of MAGI1 was linked with progression of kidney cancer [263], but decrease expression of this gene may be responsible for pathogenesis of WT. Our study found that DDIT4L and MRPL15 are down regulated in WT and has potential as a novel diagnostic and prognostic biomarker, and therapeutic target.

Module analysis was performed for up regulated genes. Genes such as IGF2BP1 [264] and PIR (Pirin (iron-binding nuclear protein)) [265] were linked with invasion of various cancer cells types, bur these genes may be involved in invasion of WT cells. Over expression of CCND1 was involved in pathogenesis of breast cancer [266], but high expression of this gene may be linked with progression of WT. Our study found that APRT, HBZ, EIF2S1, CUL7 and TKT are up regulated in WT and has potential as a novel diagnostic and prognostic biomarker, and therapeutic target. Similarly, module analysis was performed for down regulated genes. FANCC (fanconianemia, complementation group C) was important for advancement of WT [267].

Target gene - miRNA network was constructed and analyzed for up regulated genes. PTP4A1 was important for invasion of breast cancer cells [268], but this gene may be linked with invasion of WT cells. High expression RRM2 of was involved in advancement of cervical cancer [269], but elevated expression of this gene may be associated with development of WT. Similarly, target gene - miRNA network was constructed and analyzed for down regulated genes. ZNF703 was liable for invasion of colorectal cancer cells [270], but this gene may be responsible for invasion of WT cells.

Target gene - TF network was constructed and analyzed for up regulated genes. MAGEC2 was linked with invasion of breast cancer cells [271], but this gene may be involved in invasion of WT cells. Similarly, target gene - TF network was constructed and analyzed for down regulated genes. Methylation inactivation of tumor suppressor PLEKHO1 was responsible for advancement of gastric cancer [272], but loss of this gene may be important for pathogenesis of WT. Our study found that CACHD1 and CASD1 are down regulated in WT and has potential as a novel diagnostic and prognostic biomarker, and therapeutic target.

In the current investigation, the DEGs between WT and normal tissue samples in the GSE60850 dataset were determined, and the up and down regulated hub genes among the DEGs were demonstrated to be associated with the prognosis and diagonsis of patients with WT. Furthermore, FN1, AURKA, TRIM41, NFKBIA, TXNDC5, SIN3A, MAGI1, GPRASP2, UCHL1 and FXYD6 were identified as possible candidate biomarkers for patients with WT. High FN1, AURKA, TRIM41, NFKBIA, TXNDC5 mRNA expression levels 
and Iow SIN3A, MAGI1, GPRASP2, UCHL1 and FXYD6 mRNA expression levels were validated by TCGA database, human protein atlas database and subsequent ROC analysis and RT-qPCR analysis, which may preliminarily discover the pathophysiological role of these hub genes in WT at the molecular level.

In conclusion, 988 DEGs and 10 hub genes were identified as potential diagnostic or prognostic biomarkers of WT. The current investigation identified several genes which had not been already associated with WT and implemented evidence that these genes were associated with this disease. Encourage examines are recommended to authenticate these results and to more precisely analyze the associations between these genes and WT. Overall, the current investigation highlights possibly new targets for more individualized treatment of patients with WT.

\section{Declarations}

\section{Acknowledgement}

I thank Richard Dafydd Williams, UCL Institute of Child Health, Developmental Biology and Cancer, 30 Guilford Street, London, United Kingdom, very much, the author who deposited their microarray dataset, GSE60850, into the public GEO database.

\section{Conflict of interest}

The authors declare that they have no conflict of interest.

\section{Ethical approval}

This article does not contain any studies with human participants or animals performed by any of the authors.

\section{Informed consent}

No informed consent because this study does not contain human or animals participants.

\section{Availability of data and materials}

The datasets supporting the conclusions of this article are available in the GEO (Gene Expression Omnibus) (https://www.ncbi.nlm.nih.gov/geo/) repository. [(GSE60850) (https://www.ncbi.nlm.nih.gov/geo/query/acc.cgi?acc= GSE60850)]

\section{Consent for publication}

Not applicable.

\section{Competing interests}

The authors declare that they have no competing interests. 


\section{Author Contributions}

B. V. - Writing original draft, and review and editing

C. V. - Software and investigation

I. K. - Supervision and resources

\section{Authors}

Basavaraj Vastrad

Chanabasayya Vastrad

Iranna Kotturshetti
ORCID ID: 0000-0003-2202-7637

ORCID ID: 0000-0003-3615-4450

ORCID ID: 0000-0003-1988-7345

\section{References}

1. Ford K, Gunawardana S, Manirambona E Philipoh GS Mukama B Kanyamuhunga A Cartledge P, Nyoni MJ, Mwaipaya D, Mpwaga J et al. Investigating Wilms' Tumours Worldwide: A Report of the OxPLORE Collaboration-A Cross-Sectional Observational Study. World J Surg. 2019. doi:1007/s00268-019-05213-6

2. Rivera MN, Haber DA. Wilms' tumour: connecting tumorigenesis and organ development in the kidney. Nat Rev Cancer. 2005;5(9):699-712. doi:1038/nrc1696

3. McNeil DE, Brown M, Ching A, DeBaun MR.Screening for Wilms tumor and hepatoblastoma in children with Beckwith-Wiedemann syndromes: a cost-effective model. Med Pediatr Oncol. 2001;37(4):349-356. doi:1002/mpo.1209

4. Kaste SC, Dome JS, Babyn PS, Graf NM, Grundy P, Godzinski J, Levitt GA, Jenkinson H. Wilms tumour: prognostic factors, staging, therapy and late effects.Pediatr Radiol. 2008;38(1):2-17. doi:1007/s00247-007-0687-7

5. Ogawa O, Eccles MR, Szeto J, McNoe LA, Yun K, Maw MA, Smith PJ, Reeve AE. Relaxation of insulinlike growth factor II gene imprinting implicated in Wilms' tumour. 1993;362(6422):749-751. doi:10.1038/362749a0

6. Pelletier J, Bruening W, Li FP, Haber DA, Glaser T, Housman DE. WT1 mutations contribute to abnormal genital system development and hereditary Wilms' tumour. Nature. 1991;353(6343):431434. doi:1038/353431a0

7. Wagner KJ, Cooper WN, Grundy RG, Caldwell G, Jones C, Wadey RB, Morton D, Schofield PN, Reik W, Latif $\mathrm{F}$ et al. Frequent RASSF1A tumour suppressor gene promoter methylation in Wilms' tumour and colorectal cancer. Oncogene. 2002;21(47):7277-7282. doi:1038/sj.onc.1205922

8. Hanks S, Perdeaux ER, Seal S, Ruark E, Mahamdallie SS, Murray A, Ramsay E, Del Vecchio Duarte S, Zachariou A, de Souza B et al. Germline mutations in the PAF1 complex gene CTR9 predispose to 
Wilms tumour. Nat Commun. 2014;5:4398. doi:1038/ncomms5398

9. Rakheja D, Chen KS, Liu Y, Shukla AA, Schmid V, Chang TC, Khokhar S, Wickiser JE, Karandikar NJ, Malter JS et al. Somatic mutations in DROSHA and DICER1 impair microRNA biogenesis through distinct mechanisms in Wilms tumours. Nat Commun. 2017;8:16177. doi:1038/ncomms16177

10. Schweigert A, Fischer C, Mayr D, von Schweinitz D, Kappler R, Hubertus J. Activation of the Wnt/ $\beta$ catenin pathway is common in wilms tumor, but rarely through $\beta$-catenin mutation and APC promoter methylation. Pediatr Surg Int. 2016;32(12):1141-1146. doi:1007/s00383-016-3970-6

11. Maschietto M, Charlton J, Perotti D, Radice P, Geller JI, Pritchard-Jones K, Weeks M. The IGF signalling pathway in Wilms tumours-a report from the ENCCA Renal Tumours Biology-driven drug development workshop. Oncotarget. 2014;5(18):8014-8026. doi:18632/oncotarget.2485

12. Li MH, Sanchez T, Yamase H, Hla T, Oo ML, Pappalardo A, Lynch KR, Lin CY, Ferrer F. S1P/S1P1 signaling stimulates cell migration and invasion in Wilms tumor. Cancer Lett. 2009;276(2):171-179. doi:1016/j.canlet.2008.11.025

13. Liu GL, Yang HJ, Liu B, Liu T. Effects of MicroRNA-19b on the Proliferation, Apoptosis, and Migration of Wilms' Tumor Cells Via the PTEN/PI3K/AKT Signaling Pathway. J Cell Biochem. 2017;118(10):3424-3434. doi:1002/jcb.25999

14. Nowicki M, Ostalska-Nowicka D, Kaczmarek M, Miskowiak B, Witt M. The significance of VEGFC/VEGFR-2 interaction in the neovascularization and prognosis of nephroblastoma (Wilms' tumour). Histopathology. 2007;50(3):358-364. doi:1111/j.1365-2559.2007.02613.x

15. Wang WJ, Li HT, Yu JP, Li YM, Han XP, Chen P, Yu WW, Chen WK, Jiao ZY, Liu HB. Identification of key genes and associated pathways in KIT/PDGFRA wild-type gastrointestinal stromal tumors through bioinformatics analysis. Mol Med Rep. 2018;18(5):4499-4515. doi:3892/mmr.2018.9457

16. Li YL, Jin YF, Liu XX, Li HJ. A comprehensive analysis of Wnt/ß-catenin signaling pathway-related genes and crosstalk pathways in the treatment of As2O3 in renal cancer. Ren Fail. 2018;40(1):331339. doi:1080/0886022X.2018.1456461

17. Ritchie ME, Phipson B, Wu D, Hu Y, Law CW, Shi W, Smyth GK. limma powers differential expression analyses for RNA-sequencing and microarray studies. Nucleic Acids Res. 2015;43(7):e47. doi:1093/nar/gkv007

18. Karp PD, Billington R, Caspi R, Fulcher CA, Latendresse M, Kothari A, Keseler IM, Krummenacker M, Midford PE, Ong Q et al. The BioCyc collection of microbial genomes and metabolic pathways. Brief Bioinform. 2019;20(4):1085-1093. doi:1093/bib/bbx085

19. Aoki-Kinoshita KF, Kanehisa M. Gene annotation and pathway mapping in KEGG. Methods Mol Biol. 2007;396:71-91. doi:1007/978-1-59745-515-2_6

20. Schaefer CF, Anthony K, Krupa S, Buchoff J, Day M, Hannay T, Buetow KH. PID: the Pathway Interaction Database. Nucleic Acids Res. 2009;37(Database issue):D674-D679. doi:1093/nar/gkn653

21. Croft D, O'Kelly G, Wu G, Haw R, Gillespie M, Matthews L, Caudy M, Garapati P, Gopinath G, Jassal B et al. Reactome: a database of reactions, pathways and biological processes. Nucleic Acids Res. 2011;39(Database issue):D691-D697. doi:1093/nar/gkq1018 
22. Liberzon A, Subramanian A, Pinchback R, Thorvaldsdóttir H, Tamayo P, Mesirov JP. Molecular signatures database (MSigDB) 3.0. Bioinformatics. 2011;27(12):1739-1740.

doi:1093/bioinformatics/btr260

23. Dahlquist KD, Salomonis N, Vranizan K, Lawlor SC, Conklin BR. GenMAPP, a new tool for viewing and analyzing microarray data on biological pathways. Nat Genet. $2002 ; 31(1): 19-20$. doi:1038/ng050219

24. Petri V, Jayaraman P, Tutaj M, Hayman GT, Smith JR, De Pons J, Laulederkind SJ, Lowry TF, Nigam R, Wang SJ et al. The pathway ontology - updates and applications. J Biomed Semantics. 2014;5(1):7. doi:1186/2041-1480-5-7

25. Mi H, Muruganujan A, Thomas PD. PANTHER in 2013: modeling the evolution of gene function, and other gene attributes, in the context of phylogenetic trees. Nucleic Acids Res. 2013;41(Database issue):D377-D386. doi:1093/nar/gks1118

26. Chen J, Bardes EE, Aronow BJ, Jegga AG. ToppGene Suite for gene list enrichment analysis and candidate gene prioritization. Nucleic Acids Res. 2009;37(Web Server issue):W305-W311. doi:1093/nar/gkp427

27. Harris MA, Clark J, Ireland A, Lomax J, Ashburner M, Foulger R, Eilbeck K, Lewis S, Marshall B, Mungall $C$ et al. The Gene Ontology (GO) database and informatics. Nucleic Acids Res. 2004;32(Database issue):D258-D261. doi:1093/nar/gkh036

28. Calderone A, Castagnoli L, Cesareni G. mentha: a resource for browsing integrated protein-interaction networks. Nat Methods. 2013;10(8):690-691. doi:1038/nmeth.2561

29. Orchard S, Ammari M, Aranda B, Breuza L, Briganti L, Broackes-Carter F, Campbell NH, Chavali G, Chen $\mathrm{C}$, del-Toro $\mathrm{N}$ et al. The MIntAct project-IntAct as a common curation platform for 11 molecular interaction databases. Nucleic Acids Res. 2014;42(Database issue):D358-D363. doi:1093/nar/gkt1115

30. Licata L, Briganti L, Peluso D, Perfetto L, lannuccelli M, Galeota E, Sacco F, Palma A, Nardozza AP, Santonico E et al. MINT, the molecular interaction database: 2012 update. Nucleic Acids Res. 2012;40(Database issue):D857-D861. doi:1093/nar/gkr930

31. Chatr-Aryamontri A, Oughtred R, Boucher L, Rust J, Chang C, Kolas NK, O'Donnell L, Oster S, Theesfeld C, Sellam A et al. The BioGRID interaction database: 2017 update. Nucleic Acids Res. 2017;45(D1):D369-D379. doi:1093/nar/gkw1102

32. Salwinski L, Miller CS, Smith AJ, Pettit FK, Bowie JU, Eisenberg D. The Database of Interacting Proteins: 2004 update. Nucleic Acids Res. 2004;32(Database issue):D449-D451. doi:1093/nar/gkh086

33. Clerc O, Deniaud M, Vallet SD, Naba A, Rivet A, Perez S, Thierry-Mieg N, Ricard-Blum S. MatrixDB: integration of new data with a focus on glycosaminoglycan interactions. Nucleic Acids Res. 2019;47(D1):D376-D381. doi:1093/nar/gky1035

34. Shannon P, Markiel A, Ozier O, Baliga NS, Wang JT, Ramage D, Amin N, Schwikowski B, Ideker T Cytoscape: a software environment for integrated models of biomolecular interaction networks. 
Genome Res 2003;13(11):2498-2504. doi:1101/gr.1239303

35. Milenković T, Przulj N. Uncovering biological network function via graphlet degree signatures. Cancer Inform. 2008;6:257-273.

36. Hsu CW, Juan HF, Huang HC. Characterization of microRNA-regulated protein-protein interaction network. Proteomics. 2008;8(10):1975-1979. doi:1002/pmic.200701004

37. Shi Z, Zhang B. Fast network centrality analysis using GPUs. BMC Bioinformatics. 2011;12:149. doi:1186/1471-2105-12-149

38. Estrada E. Generalized walks-based centrality measures for complex biological networks. J Theor Biol. 2010;263(4):556-565. doi:1016/j.jtbi.2010.01.014

39. Stelzl U, Worm U, Lalowski M, Haenig C, Brembeck FH, Goehler H, Stroedicke M, Zenkner M, Schoenherr A, Koeppen $S$ et al. A human protein-protein interaction network: a resource for annotating the proteome. Cell. 2005;122(6):957-968. doi:1016/j.cell.2005.08.029

40. Zaki N, Efımov D, Berengueres J. Protein complex detection using interaction reliability assessment and weighted clustering coefficient. BMC. Bioinformatics. 2013,14:163. doi:1186/1471-2105-14-163

41. Zhou G, Soufan O, Ewald J, Hancock REW, Basu N, Xia J. NetworkAnalyst 3.0: a visual analytics platform for comprehensive gene expression profiling and meta-analysis. Nucleic Acids Res. 2019. doi:1093/nar/gkz240

42. Vlachos IS, Paraskevopoulou MD, Karagkouni D, Georgakilas G, Vergoulis T, Kanellos I, Anastasopoulos IL, Maniou S, Karathanou K, Kalfakakou D et al DIANA-TarBase v7.0: indexing more than half a million experimentally supported miRNA:mRNA interactions. Nucleic Acids Res. 2015;43(Database issue):D153-D159. doi:1093/nar/gku1215

43. Chou CH, Shrestha S, Yang CD, Chang NW, Lin YL, Liao KW, Huang WC, Sun TH, Tu SJ, Lee WH et al miRTarBase update 2018: a resource for experimentally validated microRNA-target interactions. Nucleic Acids Res. 2018;46(D1):D296-D302. doi:1093/nar/gkx1067

44. Lachmann A, Xu H, Krishnan J, Berger SI, Mazloom AR, Ma'ayan A. ChEA: transcription factor regulation inferred from integrating genome-wide ChIP-X experiments. Bioinformatics. 2010;26(19):2438-2444. doi:1093/bioinformatics/btq466

45. Chandrashekar DS, Bashel B, Balasubramanya SAH, Creighton CJ, Ponce-Rodriguez I, Chakravarthi BVSK, Varambally S. UALCAN: A Portal for Facilitating Tumor Subgroup Gene Expression and Survival Analyses. Neoplasia. 2017;19(8):649-658. doi:1016/j.neo.2017.05.002

46. Gao J, Aksoy BA, Dogrusoz U, Dresdner G, Gross B, Sumer SO, Sun Y, Jacobsen A, Sinha R, Larsson E et al. Integrative analysis of complex cancer genomics and clinical profiles using the cBioPortal. Sci Signal. 2013;6(269):pl1. doi:1126/scisignal.2004088

47. Uhlen M, Oksvold P, Fagerberg L, Lundberg E, Jonasson K, Forsberg M, Zwahlen M, Kampf C, Wester $\mathrm{K}$, Hober S et al. Towards a knowledge-based Human Protein Atlas. Nat Biotechnol. 2010;28(12):1248-1250. doi:1038/nbt1210-1248

48. Robin X, Turck N, Hainard A, Tiberti N, Lisacek F, Sanchez JC, Müller M. pROC: an open-source package for R and S+ to analyze and compare ROC curves. BMC Bioinformatics. 2011;12:77. 
doi:1186/1471-2105-12-77

49. Livak KJ, Schmittgen TD. Analysis of relative gene expression data using real-time quantitative PCR and the 2(-Delta Delta C(T)) Method. Methods. 2001;25(4):402-408. doi:1006/meth.2001.1262

50. Li T, Fan J, Wang B, Traugh N, Chen Q, Liu JS, Li B, Liu XS. TIMER: A Web Server for Comprehensive Analysis of Tumor-Infiltrating Immune Cells. Cancer Res. 2017;77(21):e108-e110. doi:1158/00085472.CAN-17-0307

51. Koller K, Pichler M, Koch K, Zandl M, Stiegelbauer V, Leuschner I, Hoefler G, Guertl B. Nephroblastomas show low expression of microR-204 and high expression of its target, the oncogenic transcription factor MEIS1. Pediatr Dev Pathol. 2014;17(3):169-175. doi:2350/13-01-1288OA

52. Saino M, Maruyama T, Sekiya T, Kayama T, Murakami Y. Inhibition of angiogenesis in human glioma cell lines by antisense RNA from the soluble guanylate cyclase genes, GUCY1A3 and GUCY1B3. Oncol Rep. 2004;12(1):47-52.

53. Soutto M, Chen Z, Saleh MA, Katsha A, Zhu S, Zaika A, Belkhiri A, El-Rifai W. TFF1 activates p53 through down-regulation of miR-504 in gastric cancer. Oncotarget. 2014;5(14):5663-5673. doi:18632/oncotarget.2156

54. Zhu WL, Fan BL, Liu DL, Zhu WX. Abnormal expression of fibrinogen gamma (FGG) and plasma level of fibrinogen in patients with hepatocellular carcinoma. Anticancer Res. 2009;29(7):2531-2534.

55. Malaguarnera M, Vacante M, Fichera R, Cappellani A, Cristaldi E, Motta M. Chromogranin A (CgA) serum level as a marker of progression in hepatocellular carcinoma (HCC) of elderly patients. Arch Gerontol Geriatr. 2010;51(1):81-85. doi:1016/j.archger.2009.08.004

56. Cui Y, Gao D, Linghu E, Zhan Q, Chen R, Brock MV, Herman JG, Guo M. Epigenetic changes and functional study of HOXA11 in human gastric cancer. Epigenomics. 2015;7(2):201-213. doi:2217/epi.14.92

57. Yoo KH, Park YK, Kim HS, Jung WW, Chang SG. Identification of MAPK10 as a novel epigenetic marker for chromophobe kidney cancer. Pathol Int. 2011;61(1):52-54. doi:1111/j.14401827.2010.02605.x

58. Su B, Zhao W, Shi B, Zhang Z, Yu X, Xie F, Guo Z, Zhang X, Liu J, Shen Q et al. Let-7d suppresses growth, metastasis, and tumor macrophage infiltration in renal cell carcinoma by targeting COL3A1 and CCL7. Mol Cancer. 2014;13:206. doi:1186/1476-4598-13-206

59. Basu GD, Azorsa DO, Kiefer JA, Rojas AM, Tuzmen S Barrett MT, Trent JM, Kallioniemi O, Mousses S. Functional evidence implicating S100P in prostate cancer progression. Int $\mathrm{J}$ Cancer. 2008;123(2):330-339. doi:1002/ijc.23447

60. Zhang HR, Lai SY, Huang LJ, Zhang ZF, Liu J, Zheng SR, Ding K, Bai X, Zhou JY. Myosin 1b promotes cell proliferation, migration, and invasion in cervical cancer. Gynecol Oncol. 2018;149(1):188-197. doi:1016/j.ygyno.2018.01.024

61. Chan HJ, Li H, Liu Z, Yuan YC, Mortimer J, Chen S. SERPINA1 is a direct estrogen receptor target gene and a predictor of survival in breast cancer patients. SERPINA1 is a direct estrogen receptor target 
gene and a predictor of survival in breast cancer patients. Oncotarget. 2015;6(28):25815-25827. doi:18632/oncotarget.4441

62. Repetto O, Maiero S, Magris R, Miolo G, Cozzi MR, Steffan A, Canzonieri V, Cannizzaro R, De Re V. Quantitative Proteomic Approach Targeted to Fibrinogen $\beta$ Chain in Tissue Gastric Carcinoma. Int J Mol Sci. 2018;19(3). doi:3390/ijms19030759

63. Moss AC, Jacobson GM, Walker LE, Blake NW, Marshall E, Coulson JM. SCG3 transcript in peripheral blood is a prognostic biomarker for REST-deficient small cell lung cancer. Clin Cancer Res. 2009;15(1):274-283. doi:1158/1078-0432.CCR-08-1163

64. Chong PK, Lee H, Zhou J, Liu SC, Loh MC, Wang TT, Chan SP, Smoot DT, Ashktorab H, So JB et al ITIH3 is a potential biomarker for early detection of gastric cancer. J Proteome Res. 2010;9(7):36713679. doi:1021/pr100192h

65. Ren P, Chen FF, Liu HY, Cui XL, Sun Y, Guan JL, Liu ZH, Liu JG, Wang YN. High serum levels of follistatin in patients with ovarian cancer. J Int Med Res. 2012;40(3):877-886. doi:1177/147323001204000306

66. Huang H, Han Y, Gao J, Feng J, Zhu L, Qu L, Shen L, Shou C. High level of serum AMBP is associated with poor response to paclitaxel-capecitabine chemotherapy in advanced gastric cancer patients. Med Oncol. 2013;30(4):748. doi:1007/s12032-013-0748-8

67. Cao Y, Nimptsch K, Shui IM, Platz EA, Wu K, Pollak MN, Kenfield SA, Stampfer MJ, Giovannucci EL. Prediagnostic plasma IGFBP-1, IGF-1 and risk of prostate cancer. Int J Cancer. 2015;136(10):24182426. doi:1002/ijc.29295

68. Xu XF, Guo CY, Liu J, Yang WJ, Xia YJ, Xu L, Yu YC, Wang XP. Gli1 maintains cell survival by upregulating IGFBP6 and $\mathrm{Bcl}-2$ through promoter regions in parallel manner in pancreatic cancer cells. J Carcinog. 2009;8:13. doi:4103/1477-3163.55429

69. Wang B, Xu L, Ge Y, Cai X, Li Q, Yu Z, Wang J, Wang Y, Lu C, Wang D et al. PLOD3 is Upregulated in Gastric Cancer and Correlated with Clinicopathologic Characteristics. Clin Lab. 2019;65(1). doi:7754/Clin.Lab.2018.180541

70. Wang X, Luo L, Dong D, Yu Q, Zhao K. Clusterin plays an important role in clear renal cell cancer metastasis. Urol Int. 2014;92(1):95-103. doi:1159/000351923

71. Wei F, Wu Y, Tang L, He Y, Shi L, Xiong F, Gong Z, Guo C, Li X, Liao Q et al BPIFB1 (LPLUNC1) inhibits migration and invasion of nasopharyngeal carcinoma by interacting with VTN and VIM. $\mathrm{Br} J$ Cancer. 2018;118(2):233-247. doi:1038/bjc.2017.385

72. Azimi I., Petersen RM., Thompson EW., Roberts-Thomson SJ4, Monteith GR. Hypoxia-induced reactive oxygen species mediate $\mathrm{N}$-cadherin and SERPINE1 expression, EGFR signalling and motility in MDA-MB-468 breast cancer cells. Sci Rep. 2017;7(1):15140. doi:1038/s41598-017-15474-7

73. Wang K, Wang B, Xing AY, Xu KS, Li GX, Yu ZH. Prognostic significance of SERPINE2 in gastric cancer and its biological function in SGC7901 cells. J Cancer Res Clin Oncol. 2015;141(5):805-812. doi:1007/s00432-014-1858-1 
74. Zhang H, Sun Z, Li Y, Fan D, Jiang H. MicroRNA-200c binding to FN1 suppresses the proliferation, migration and invasion of gastric cancer cells. Biomed Pharmacother. 2017;88:285-292. doi:1016/j.biopha.2017.01.023

75. Poettler M, Unseld M, Braemswig K, Haitel A, Zielinski CC, Prager GW. CD98hc (SLC3A2) drives integrin-dependent renal cancer cell behavior. Mol Cancer. 2013;12:169. doi:1186/1476-4598-12-169

76. Chuang YC, Wu HY, Lin YL, Tzou SC, Chuang CH, Jian TY, Chen PR, Chang YC, Lin CH, Huang TH et al. Blockade of ITGA2 Induces Apoptosis and Inhibits Cell Migration in Gastric Cancer. Biol Proced Online. 2018;20:10. doi:1186/s12575-018-0073-x

77. Koshizuka K, Hanazawa T, Kikkawa N, Arai T, Okato A, Kurozumi A, Kato M, Katada K, Okamoto Y, Seki $\mathrm{N}$ et al. Regulation of ITGA3 by the anti-tumor miR-199 family inhibits cancer cell migration and invasion in head and neck cancer. Cancer Sci. 2017;108(8):1681-1692. doi:1111/cas.13298

78. Yoo HI, Kim BK, Yoon SK. MicroRNA-330-5p negatively regulates ITGA5 expression in human colorectal cancer. Oncol Rep. 2016;36(5):3023-3029. doi:3892/or.2016.5092

79. El Haibi CP, Sharma PK, Singh R, Johnson PR, Suttles J, Singh S, Lillard JW Jr. PI3Kp110-, Src-, FAKdependent and DOCK2-independent migration and invasion of CXCL13-stimulated prostate cancer cells. Mol Cancer. 2010;9:85. doi:1186/1476-4598-9-85

80. Bondong S, Kiefel H, Hielscher T, Zeimet AG, Zeillinger R, Pils D, Schuster E, Castillo-Tong DC, Cadron I, Vergote I et al. Prognostic significance of L1CAM in ovarian cancer and its role in constitutive NFKB activation. Ann Oncol. 2012;23(7):1795-802. doi:1093/annonc/mdr568

81. Butz H, Szabó PM, Khella HW, Nofech-Mozes R, Patocs A, Yousef GM. miRNA-target network reveals miR-124as a key miRNA contributing to clear cell renal cell carcinoma aggressive behaviour by targeting CAV1 and FLOT1. Oncotarget. 2015;6(14):12543-12557. doi:18632/oncotarget.3815

82. Wuttig D, Zastrow S, Füssel S, Toma MI, Meinhardt M, Kalman K, Junker K, Sanjmyatav J, Boll K, Hackermüller $\mathrm{J}$ et al. CD31, EDNRB and TSPAN7 are promising prognostic markers in clear-cell renal cell carcinoma revealed by genome-wide expression analyses of primary tumors and metastases. Int J Cancer. 2012;131(5):E693-E704. doi:1002/ijc.27419

83. Yu ST., Zhong Q., Chen RH., Han P., Li SB., Zhang H., Yuan L, Xia TL, Zeng MS, Huang XM. CRLF1 promotes malignant phenotypes of papillary thyroid carcinoma by activating the MAPK/ERK and PI3K/AKT pathways. Cell Death Dis. 2018;9(3):371. doi:1038/s41419-018-0352-0

84. Liu CL, Pan HW, Torng PL, Fan MH, Mao TL. SRPX and HMCN1 regulate cancer-associated fibroblasts to promote the invasiveness of ovarian carcinoma. Oncol Rep. 2019. doi:3892/or.2019.7379

85. Bie F, Wang G, Qu X, Wang Y, Huang C, Wang Y, Du J. Loss of FGL1 induces epithelial-mesenchymal transition and angiogenesis in LKB1 mutant lung adenocarcinoma. Int J Oncol. 2019;55(3):697-707. doi:3892/ijo.2019.4838

86. Cheng XS, Li YF, Tan J, Sun B, Xiao YC, Fang XB, Zhang XF, Li Q, Dong JH, Li M et al. CCL20 and CXCL8 synergize to promote progression and poor survival outcome in patients with colorectal 
cancer by collaborative induction of the epithelial-mesenchymal transition. Cancer Lett. 2014;348(12):77-87. doi:1016/j.canlet.2014.03.008

87. Ao R, Guan L, Wang Y, Wang JN. Silencing of COL1A2, COL6A3, and THBS2 inhibits gastric cancer cell proliferation, migration, and invasion while promoting apoptosis through the PI3k-Akt signaling pathway. J Cell Biochem. 2018;119(6):4420-4434. doi:1002/jcb.26524

88. Malik MF, Satherley LK, Davies EL, Ye L, Jiang WG. Expression of Semaphorin 3C in Breast Cancer and its Impact on Adhesion and Invasion of Breast Cancer Cells. Anticancer Res. 2016;36(3):12811286.

89. Li C., Wang J., Kong J., Tang J., Wu Y, Xu E, Zhang H, Lai M. GDF15 promotes EMT and metastasis in colorectal cancer. Oncotarget. 2016;7(1):860-872. doi:18632/oncotarget.6205

90. Hua K, Li Y, Zhao Q, Fan L, Tan B, Gu J. Downregulation of Annexin A11 (ANXA11) Inhibits Cell Proliferation, Invasion, and Migration via the AKT/GSK-3 $\beta$ Pathway in Gastric Cancer. Med Sci Monit. 2018;24:149-160. doi:12659/msm.905372

91. Zeng B, Zhou M, Wu H, Xiong Z. SPP1 promotes ovarian cancer progression via Integrin $\beta 1 / F A K / A K T$ signaling pathway. Onco Targets Ther. 2018;11:1333-1343. doi:2147/OTT.S154215

92. Meng X, Chen X, Lu P, Ma W, Yue D, Song L, Fan Q. MicroRNA-202 inhibits tumor progression by targeting LAMA1 in esophageal squamous cell carcinoma. Biochem Biophys Res Commun. 2016;473(4):821-827. doi:1016/j.bbrc.2016.03.130

93. Miyoshi N, Ishii H, Mimori K, Sekimoto M, Doki Y, Mori M. TDGF1 is a novel predictive marker for metachronous metastasis of colorectal cancer. Int J Oncol. 2010;36(3):563-568. doi:3892/ijo_00000530

94. Xin H, Cao Y, Shao ML, Zhang W, Zhang CB, Wang JT, Liang LC, Shao WW, Qi YL, Li Y et al. Chemokine CXCL3 mediates prostate cancer cells proliferation, migration and gene expression changes in an autocrine/paracrine fashion. Int Urol Nephrol. 2018;50(5):861-868. doi:1007/s11255018-1818-9

95. Han L, Wu Z, Zhao Q. Revealing the molecular mechanism of colorectal cancer by establishing LGALS3-related protein-protein interaction network and identifying signaling pathways. Int J Mol Med. 2014;33(3):581-588. doi:3892/ijmm.2014.1620

96. Huasong G, Zongmei D, Jianfeng H, Xiaojun Q, Jun G, Sun G, Donglin W, Jianhong Z. Serine protease inhibitor (SERPIN) B1 suppresses cell migration and invasion in glioma cells. Brain Res. 2015;1600:59-69. doi:1016/j.brainres.2014.06.017

97. Wit M, Belt EJ, Delis-van Diemen PM, Carvalho B, Coupé VM, Stockmann HB, Bril H, Beliën JA, Fijneman RJ, Meijer GA. Lumican and versican are associated with good outcome in stage II and III colon cancer. Ann Surg Oncol. 2013;20 Suppl 3:S348-S359. doi:1245/s10434-012-2441-0

98. Hagelgans A, Jandeck C, Friedemann M, Donchin A, Richter S, Menschikowski M. Identification of CpG Sites of SERPINA5 Promoter with Opposite Methylation Patterns in Benign and Malignant Prostate Cells. Anticancer Res. 2017;37(12):6609-6618. doi:21873/anticanres.12118 
99. Soh MA, Garrett SH, Somji S, Dunlevy JR, Zhou XD, Sens MA, Bathula CS, Allen C, Sens DA. Arsenic, cadmium and neuron specific enolase (ENO2, $\gamma$-enolase) expression in breast cancer. Cancer Cell Int. 2011;11(1):41. doi:1186/1475-2867-11-41

100. Ma Y, Chen Y, Petersen I. Expression and epigenetic regulation of cystatin $B$ in lung cancer and colorectal cancer. Pathol Res Pract. 2017;213(12):1568-1574. doi:1016/j.prp.2017.06.007

101. Fribbens C, O'Leary B, Kilburn L, Hrebien S, Garcia-Murillas I, Beaney M, Cristofanilli M, Andre F, Loi S, Loibl S et al. Plasma ESR1 Mutations and the Treatment of Estrogen Receptor-Positive Advanced Breast Cancer. J Clin Oncol. 2016;34(25):2961-2968. doi:1200/JC0.2016.67.3061

102. Barbieri CE, Baca SC, Lawrence MS, Demichelis F, Blattner M, Theurillat JP, White TA, Stojanov P, Van Allen E, Stransky $\mathrm{N}$ et al. Exome sequencing identifies recurrent SPOP, FOXA1 and MED12 mutations in prostate cancer. Nat Genet. 2012;44(6):685-689. doi:1038/ng.2279

103. Gao F, Liu QC, Zhang S, Zhuang ZH, Lin CZ, Lin XH. PRSS1 intron mutations in patients with pancreatic cancer and chronic pancreatitis. Mol Med Rep. 2012;5(2):449-451.

doi:3892/mmr.2011.684

104. Lei Q, Jiao J, Xin L, Chang CJ, Wang S, Gao J, Gleave ME, Witte ON, Liu X, Wu H. NKX3.1 stabilizes p53, inhibits AKT activation, and blocks prostate cancer initiation caused by PTEN loss. Cancer Cell. 2006;9(5):367-378. doi:1016/j.ccr.2006.03.031

105. Peters I, Dubrowinskaja N, Tezval H, Kramer MW, von Klot CA, Hennenlotter J, Stenzl A, Scherer R, Kuczyk MA, Serth J. Decreased mRNA expression of GATA1 and GATA2 is associated with tumor aggressiveness and poor outcome in clear cell renal cell carcinoma. Target Oncol. 2015;10(2):267275. doi:1007/s11523-014-0335-8

106. Kammerer R, Riesenberg R, Weiler C, Lohrmann J, Schleypen J, Zimmermann W. The tumour suppressor gene CEACAM1 is completely but reversibly downregulated in renal cell carcinoma. $\mathrm{J}$ Pathol. 2004;204(3):258-267. doi:1002/path.1657

107. Worst TS, Meyer Y, Gottschalt M, Weis CA, von Hardenberg J, Frank C, Steidler A, Michel MS, Erben P. RAB27A, RAB27B and VPS36 are downregulated in advanced prostate cancer and show functional relevance in prostate cancer cells. Int J Oncol. 2017;50(3):920-932. doi:3892/ijo.2017.3872

108. Song Q, Li C, Feng X, Yu A, Tang H, Peng Z, Wang X. Decreased expression of SCUBE2 is associated with progression and prognosis in colorectal cancer. Oncol Rep. 2015;33(4):1956-1964. doi:3892/or.2015.3790

109. Wei WF, Zhou CF, Wu XG, He LN, Wu LF, Chen XJ, Yan RM, Zhong M, Yu YH, Liang L et al. MicroRNA221-3p, a TWIST2 target, promotes cervical cancer metastasis by directly targeting THBS2. Cell Death Dis. 2017;8(12):3220. doi:1038/s41419-017-0077-5

110. Ricketts C, Zeegers MP, Lubinski J, Maher ER. Analysis of germline variants in CDH1, IGFBP3, MMP1, MMP3, STK15 and VEGF in familial and sporadic renal cell carcinoma. PLoS One. 2009;4(6):e6037. doi:1371/journal.pone.0006037

111. Hsu MC, Lee KT, Hsiao WC, Wu CH, Sun HY, Lin IL, Young KC. The dyslipidemia-associated SNP on the APOA1/C3/A5 gene cluster predicts post-surgery poor outcome in Taiwanese breast cancer 
patients: a 10-year follow-up study. BMC Cancer. 2013;13:330. doi:1186/1471-2407-13-330

112. Yang Y, Chang TY, Chen TC, Lin WS, Chang SC, Lee YJ. ITPR3 gene haplotype is associated with cervical squamous cell carcinoma risk in Taiwanese women. Oncotarget. 2017;8(6):10085-10090. doi:18632/oncotarget.14341

113. Safarinejad MR. Insulin-like growth factor binding protein-3 (IGFBP-3) gene variants are associated with renal cell carcinoma. BJU Int. 2011;108(5):762-70. doi:1111/j.1464-410X.2010.10017.x

114. Chen Y, Kibriya MG, Jasmine F, Santella RM, Senie RT, Ahsan H. Do placental genes affect maternal breast cancer? Association between offspring's CGB5 and CSH1 gene variants and maternal breast cancer risk. Cancer Res. 2008;68(23):9729-9734. doi:1158/0008-5472.CAN-08-2243

115. Shen N, Gong J, Wang Y, Tian J, Qian J, Zou L, Chen W, Zhu B, Lu X, Zhong R et al. Integrative genomic analysis identifies that SERPINA6-rs1998056 regulated by FOXA/ERa is associated with female hepatocellular carcinoma. PLoS One. 2014;9(9):e107246. doi:1371/journal.pone.0107246

116. Rubio MP, Correa KM, Ueki K, Mohrenweiser HW, Gusella JF, von Deimling A, Louis DN. The putative glioma tumor suppressor gene on chromosome 19q maps between APOC2 and HRC. Cancer Res. 1994;54(17):4760-4763.

117. Wang L, Zhang D, Chen XR, Fan YX, Wang JX. Expression of vascular endothelial growth factor (VEGF) and VEGF-C in serum and tissue of Wilms tumor. Chin Med J (Engl). 2011;124(22):37163720.

118. Klijanienko J, Caly M, Frénaux P, Klos J. GATA3 differential expression in neuroblastoma and nephroblastoma. Cancer Cytopathol. 2018;126(3):215-216. doi:1002/cncy.21952

119. Ghanem MA, Van Steenbrugge GJ, Van Der Kwast TH, Sudaryo MK, Noordzij MA, Nijman RJ. Expression and prognostic value Of CD44 isoforms in nephroblastoma (Wilms tumor). J Urol. 2002;168(2):681-686.

120. Li HJ, Chen YX, Wang Q, Zhang YG. S100A4 mRNA as a prognostic marker and therapeutic target in Wilms tumor (WT). Eur Rev Med Pharmacol Sci. 2014;18(6):817-827.

121. Chen L, Yuan L, Wang Y, Wang G, Zhu Y, Cao R, Qian G, Xie C, Liu X, Xiao Y et al. Co-expression network analysis identified FCER1G in association with progression and prognosis in human clear cell renal cell carcinoma. Int J Biol Sci. 2017;13(11):1361-1372. doi:7150/ijbs.21657

122. Zhang Z, Wang Y, Zhang J, Zhong J, Yang R. COL1A1 promotes metastasis in colorectal cancer by regulating the WNT/PCP pathway. Mol Med Rep. 2018;17(4):5037-5042. doi:3892/mmr.2018.8533

123. Kim JH, Lkhagvadorj S, Lee MR, Hwang KH, Chung HC, Jung JH, Cha SK, Eom M5. Orai1 and STIM1 are critical for cell migration and proliferation of clear cell renal cell carcinoma. Biochem Biophys Res Commun. 2014;448(1):76-82. doi:1016/j.bbrc.2014.04.064

124. Wang JK, Wang WJ, Cai HY, Du BB, Mai P, Zhang LJ, Ma W, Hu YG, Feng SF, Miao GY. MFAP2 promotes epithelial-mesenchymal transition in gastric cancer cells by activating TGF- $\beta /$ SMAD $2 / 3$ signaling pathway. Onco Targets Ther. 2018;11:4001-4017. doi:2147/OTT.S160831

125. Wang Z, Cao CJ, Huang LL, Ke ZF, Luo CJ, Lin ZW, Wang F, Zhang YQ, Wang LT. EFEMP1 promotes the migration and invasion of osteosarcoma via MMP-2 with induction by AEG-1 via NF-KB signaling 
pathway. 2015;6(16):14191-14208. doi:10.18632/oncotarget.3691

126. Tian X, Ye C, Yang Y, Guan X, Dong B, Zhao M, Hao C. Expression of CD147 and matrix metalloproteinase-11 in colorectal cancer and their relationship to clinicopathological features. $J$ Transl Med. 2015;13:337. doi:1186/s12967-015-0702-y

127. Shioi K, Komiya A, Hattori K, Huang Y, Sano F, Murakami T, Nakaigawa N, Kishida T, Kubota Y, Nagashima $Y$ et al. Vascular cell adhesion molecule 1 predicts cancer-free survival in clear cell renal carcinoma patients. Clin Cancer Res. 2006;12(24):7339-7346. doi:1158/1078-0432.CCR-06-1737

128. Ganapathi MK, Jones WD, Sehouli J, Michener CM, Braicu IE, Norris EJ, Biscotti CV, Vaziri SA, Ganapathi RN. Expression profile of COL2A1 and the pseudogene SLC6A10P predicts tumor recurrence in high-grade serous ovarian cancer. Int J Cancer. 2016;138(3):679-88. doi:1002/ijc.29815

129. JingSong H, Hong G, Yang J, Duo Z, Li F, WeiCai C, XueYing L, YouSheng M, YiWen O, Yue P, Zou C. siRNA-mediated suppression of collagen type iv alpha 2 (COL4A2) mRNA inhibits triple-negative breast cancer cell proliferation and migration. Oncotarget. 2017;8(2):2585-2593. doi:18632/oncotarget.13716

130. Miyake M, Hori S, Morizawa Y, Tatsumi Y, Toritsuka M, Ohnishi S, Shimada K, Furuya H, Khadka VS, Deng $Y$ et al. Collagen type IV alpha 1 (COL4A1) and collagen type XIII alpha 1 (COL13A1) produced in cancer cells promote tumor budding at the invasion front in human urothelial carcinoma of the bladder. Oncotarget. 2017;8(22):36099-36114. doi:18632/oncotarget.16432

131. Dawoody Nejad L, Biglari A, Annese T, Ribatti D. Recombinant fibromodulin and decorin effects on NF-KB and TGF $\beta 1$ in the 4T1 breast cancer cell line. Oncol Lett. 2017;13(6):4475-4480. doi:3892/ol.2017.5960

132. Lu X, Wan F, Zhang H, Shi G, Ye D. ITGA2B and ITGA8 are predictive of prognosis in clear cell renal cell carcinoma patients. Tumour Biol. 2016;37(1):253-62. doi:1007/s13277-015-3792-5

133. Lee SJ, Kim BG, Choi YL, Lee JW. Increased expression of calpain 6 during the progression of uterine cervical neoplasia: immunohistochemical analysis. Oncol Rep. 2008;19(4):859-863.

134. Mertsch S, Schurgers LJ, Weber K, Paulus W, Senner V. Matrix gla protein (MGP): an overexpressed and migration-promoting mesenchymal component in glioblastoma. BMC Cancer. 2009;9:302. doi:1186/1471-2407-9-302

135. Dai W, Huang HL, Hu M, Wang SJ, He HJ, Chen NP, Li MY. microRNA-506 regulates proliferation, migration and invasion in hepatocellular carcinoma by targeting F-spondin 1 (SPON1). Am J Cancer Res. 2015;5(9):2697-707.

136. Huang T, Wang L, Liu D, Li P, Xiong H, Zhuang L, Sun L, Yuan X, Qiu H. FGF7/FGFR2 signal promotes invasion and migration in human gastric cancer through upregulation of thrombospondin-1. Int $\mathrm{J}$ Oncol. 2017;50(5):1501-1512. doi:3892/ijo.2017.3927

137. Tian TV, Tomavo N, Huot L, Flourens A, Bonnelye E, Flajollet S, Hot D, Leroy X, de Launoit Y, DuterqueCoquillaud M. Identification of novel TMPRSS2:ERG mechanisms in prostate cancer metastasis: involvement of MMP9 and PLXNA2. Oncogene. 2014;33(17):2204-2214. doi:1038/onc.2013.176 
138. Struckmann K, Mertz K, Steu S, Storz M, Staller P, Krek W, Schraml P, Moch H. pVHL co-ordinately regulates CXCR4/CXCL12 and MMP2/MMP9 expression in human clear-cell renal cell carcinoma. J Pathol. 2008;214(4):464-471. doi:1002/path.2310

139. Yao J, Hu XF, Feng XS, Gao SG. Pleiotrophin promotes perineural invasion in pancreatic cancer. World J Gastroenterol. 2013;19(39):6555-6558. doi:3748/wjg.v19.i39.6555

140. Liu YP, Chen WD, Li WN, Zhang M. Overexpression of FNDC1 Relates to Poor Prognosis and Its Knockdown Impairs Cell Invasion and Migration in Gastric Cancer. Technol Cancer Res Treat. 2019;18:1533033819869928. doi:1177/1533033819869928

141. Peng S, Du T, Wu W, Chen X, Lai Y, Zhu D, Wang Q, Ma X, Lin C, Li Z. Decreased expression of serine protease inhibitor family G1 (SERPING1) in prostate cancer can help distinguish high-risk prostate cancer and predicts malignant progression. Urol Oncol. 2018;36(8):366.e1-366.e9. doi:1016/j.urolonc.2018.05.021

142. Delic S, Lottmann N, Jetschke K, Reifenberger G, Riemenschneider MJ. Identification and functional validation of CDH11, PCSK6 and SH3GL3 as novel glioma invasion-associated candidate genes. Neuropathol Appl Neurobiol. 2012;38(2):201-212. doi:1111/j.1365-2990.2011.01207.x

143. Kojima T, Shimazui T, Horie R, Hinotsu S, Oikawa T, Kawai K, Suzuki H, Meno K, Akaza H, Uchida K. FOX01 and TCF7L2 genes involved in metastasis and poor prognosis in clear cell renal cell carcinoma. Genes Chromosomes Cancer. 2010;49(4):379-389. doi:1002/gcc.20750

144. Wang SY, Gao K, Deng DL, Cai JJ, Xiao ZY, He LQ, Jiao HL, Ye YP, Yang RW, Li TT et al. TLE4 promotes colorectal cancer progression through activation of JNK/C-Jun signaling pathway. Oncotarget. 2016;7(3):2878-2888. doi:18632/oncotarget.6694

145. Fan Y, Mu J, Huang M, Imani S, Wang Y, Lin S, Fan J, Wen Q. Epigenetic identification of ADCY4 as a biomarker for breast cancer: an integrated analysis of adenylate cyclases. Epigenomics. 2019. doi:2217/epi-2019-0207

146. Xu Z, Chen H, Liu D, Huo J. Fibulin-1 is downregulated through promoter hypermethylation in colorectal cancer: a CONSORT study. Medicine (Baltimore). 2015;94(13):e663. doi:1097/MD.0000000000000663

147. Hibi K, Mizukami H, Saito M, Kigawa G, Nemoto H, Sanada Y. FBN2 methylation is detected in the serum of colorectal cancer patients with hepatic metastasis. Anticancer Res. 2012;32(10):43714374.

148. Lung HL, Lo PHY, Xie D, Apte SS, Cheung AKL, Cheng Y, Law EWL, Chua D, Zeng YX, Tsao SW et al. Characterization of a novel epigenetically-silenced, growth-suppressive gene, ADAMTS9, and its association with lymph node metastases in nasopharyngeal carcinoma. Int J Cancer. 2008;123(2):401-408. doi:1002/ijc.23528

149. Nakamura R, Oyama T, Tajiri R, Mizokami A, Namiki M, Nakamoto M, Ooi A. Expression and regulatory effects on cancer cell behavior of NELL1 and NELL2 in human renal cell carcinoma. Cancer Sci. 2015;106(5):656-664. doi:1111/cas.12649 
150. Zhou D, Tang W., Su G, Cai M, An HX, Zhang Y. PCDH18 is frequently inactivated by promoter methylation in colorectal cancer. Sci Rep. 2017;7(1):2819. doi:1038/s41598-017-03133-w

151. Fosbury E, Szychot E, Slater O, Mathias M, Sibson K. An 11-year experience of acquired von Willebrand syndrome in children diagnosed with Wilms tumour in a tertiary referral centre. Pediatr Blood Cancer. 2017;64(3). doi:1002/pbc.26246

152. Senanayake U, Das S, Vesely P, Alzoughbi W, Fröhlich LF, Chowdhury P, Leuschner I, Hoefler G, Guertl B. miR-192, miR-194, miR-215, miR-200c and miR-141 are downregulated and their common target ACVR2B is strongly expressed in renal childhood neoplasms. Carcinogenesis. 2012;33(5):1014-1021. doi:1093/carcin/bgs126

153. Messai Y, Noman MZ, Janji B, Hasmim M, Escudier B, Chouaib S. The autophagy sensor ITPR1 protects renal carcinoma cells from NK-mediated killing. Autophagy. 2015. doi:1080/15548627.2015.1017194

154. Yu Y, Gaillard S, Phillip JM, Huang TC, Pinto SM, Tessarollo NG, Zhang Z, Pandey A, Wirtz D, Ayhan A et al. Inhibition of Spleen Tyrosine Kinase Potentiates Paclitaxel-Induced Cytotoxicity in Ovarian Cancer Cells by Stabilizing Microtubules. Cancer Cell. 2015;28(1):82-96. doi:1016/j.ccell.2015.05.009

155. Liao CH, Chang WS, Hu PS, Wu HC, Hsu SW, Liu YF, Liu SP, Hung HS, Bau DT, Tsai CW. The Contribution of MMP-7 Promoter Polymorphisms in Renal Cell Carcinoma. In Vivo. 2017;31(4):631635. doi:21873/invivo.11104

156. Azzato EM, Lee AJ, Teschendorff A, Ponder BA, Pharoah P, Caldas C, Maia AT. Common germ-line polymorphism of C1QA and breast cancer survival. Br J Cancer. 2010;102(8):1294-1299. doi:1038/sj.bjc. 6605625

157. Zhang L, Jiang H, Xu G, Wen H, Gu B, Liu J, Mao S, Na R, Jing Y, Ding Q et al. Proteins S100A8 and S100A9 are potential biomarkers for renal cell carcinoma in the early stages: results from a proteomic study integrated with bioinformatics analysis. Mol Med Rep. 2015;11(6):4093-4100. doi:3892/mmr.2015.3321

158. Liang W, Yang C, Peng J, Qian Y, Wang Z. The Expression of HSPD1, SCUBE3, CXCL14 and Its Relations with the Prognosis in Osteosarcoma. Cell Biochem Biophys. 2015;73(3):763-768. doi:1007/s12013-015-0579-7

159. Wright JH, Johnson MM, Shimizu-Albergine M, Bauer RL, Hayes BJ, Surapisitchat J, Hudkins KL, Riehle KJ, Johnson SC, Yeh MM et al. Paracrine activation of hepatic stellate cells in platelet-derived growth factor $\mathrm{C}$ transgenic mice: evidence for stromal induction of hepatocellular carcinoma. Int $\mathrm{J}$ Cancer. 2014;134(4):778-788. doi:1002/ijc.28421

160. Zhang C, Li S, Qiao B, Yang K, Liu R, Ma B, Liu Y, Zhang Z, Xu Y. CtBP2 overexpression is associated with tumorigenesis and poor clinical outcome of prostate cancer. Arch Med Sci. 2015;11(6):13181323. doi:5114/aoms.2015.56359

161. Ye H, Wang WG, Cao J, Hu XC. SPARCL1 suppresses cell migration and invasion in renal cell carcinoma. Mol Med Rep. 2017;16(5):7784-7790. doi:3892/mmr.2017.7535 
162. Xiang RH, Hensel CH, Garcia DK, Carlson HC, Kok K, Daly MC, Kerbacher K, van den Berg A, Veldhuis $\mathrm{P}$, Buys $\mathrm{CH}$ et al. Isolation of the human semaphorin III/F gene (SEMA3F) at chromosome 3p21, a region deleted in lung cancer. Genomics. 1996;32(1):39-48. doi:1006/geno.1996.0074

163. Wang C, Chen Q, Li S, Li S, Zhao Z, Gao H, Wang X, Li B, Zhang W, Yuan Y et al. Dual inhibition of PCDH9 expression by miR-215-5p up-regulation in gliomas. Oncotarget. 2017;8(6):10287-10297. doi:18632/oncotarget.14396

164. Piao S, Inglehart RC, Scanlon CS, Russo N, Banerjee R, D'Silva NJ. CDH11 inhibits proliferation and invasion in head and neck cancer. J Oral Pathol Med. 2017;46(2):89-97. doi:1111/jop.12471

165. Zhao Z, Zhang M, Duan X, Deng T, Qiu H, Zeng G. Low NR3C2 levels correlate with aggressive features and poor prognosis in non-distant metastatic clear-cell renal cell carcinoma. J Cell Physiol. 2018;233(10):6825-6838. doi:1002/jcp.26550

166. Kim GH, Won JE, Byeon Y, Kim MG, Wi TI, Lee JM, Park YY, Lee JW, Kang TH, Jung ID et al. Selective delivery of PLXDC1 small interfering RNA to endothelial cells for anti-angiogenesis tumor therapy using CD44-targeted chitosan nanoparticles for epithelial ovarian cancer. Drug Deliv. 2018;25(1):1394-1402. doi:1080/10717544.2018.1480672

167. Li X, Lin R, Li J. Epigenetic silencing of microRNA-375 regulates PDK1 expression in esophageal cancer. Dig Dis Sci. 2011;56(10):2849-2856. doi:1007/s10620-011-1711-1

168. Li M, Zhang Z, Yuan J, Zhang Y, Jin X. Altered glutamate cysteine ligase expression and activity in renal cell carcinoma. Biomed Rep. 2014;2(6):831-834. doi:3892/br.2014.359

169. Lu Z, Xiao Z, Liu F, Cui M, Li W, Yang Z Li J, Ye L, Zhang X. Long non-coding RNA HULC promotes tumor angiogenesis in liver cancer by up-regulating sphingosine kinase 1 (SPHK1). Oncotarget. 2016;7(1):241-254. doi:18632/oncotarget.6280

170. Bey EA, Bentle MS, Reinicke KE, Dong Y, Yang CR, Girard L, Minna JD, Bornmann WG, Gao J, Boothman DA. An NQ01- and PARP-1-mediated cell death pathway induced in non-small-cell lung cancer cells by beta-lapachone. Proc Natl Acad Sci U S A. 2007;104(28):11832-11837. doi:1073/pnas.0702176104

171. Chakraborty PK, Xiong X, Mustafi SB, Saha S, Dhanasekaran D, Mandal NA, McMeekin S, Bhattacharya R, Mukherjee P. Role of cystathionine beta synthase in lipid metabolism in ovarian cancer. Oncotarget. 2015;6(35):37367-37384. doi:18632/oncotarget.5424

172. Zhu Z, He A, Lv T, Xu C, Lin L, Lin J.Overexpression of P4HB is correlated with poor prognosis in human clear cell renal cell carcinoma. Cancer Biomark. 2019. doi:3233/CBM-190450

173. Zhao J, Li J, Fan TWM, Hou SX. Glycolytic reprogramming through PCK2 regulates tumor initiation of prostate cancer cells. Oncotarget. 2017;8(48):83602-83618. doi:18632/oncotarget.18787

174. Pirinççi N, Kaya TY, Kaba M, Ozan T, Geçit I, Özveren H, Eren H, Ceylan K. Serum adenosine deaminase, catalase, and carbonic anhydrase activities in patients with renal cell carcinoma. Redox Rep 2017;22(6):252-256. doi:1080/13510002.2016.1207364

175. Nikitenko LL, Leek R, Henderson S, Pillay N, Turley H, Generali D, Gunningham S, Morrin HR, Pellagatti A, Rees MC et al. The G-protein-coupled receptor CLR is upregulated in an autocrine loop with 
adrenomedullin in clear cell renal cell carcinoma and associated with poor prognosis. Clin Cancer Res. 2013;19(20):5740-5748. doi:1158/1078-0432.CCR-13-1712

176. Salmans ML, Zhao F, Andersen B. The estrogen-regulated anterior gradient 2 (AGR2) protein in breast cancer: a potential drug target and biomarker. Breast Cancer Research. 2013;15(2):204. doi:1186/bcr3408

177. Chang YT, Wu CC, Shyr YM, Chen TC, Hwang TL, Yeh TS, Chang KP, Liu HP, Liu YL, Tsai MH et al. Secretome-based identification of ULBP2 as a novel serum marker for pancreatic cancer detection. PloS one. 2011;6(5):e20029. doi:1371/journal.pone.0020029

178. Laczmanska I, Karpinski P, Gil J, Laczmanski L, Bebenek M, Sasiadek MM. High PTPRQ expression and its relationship to expression of PTPRZ1 and the presence of KRAS mutations in colorectal cancer tissues. Anticancer research. 2016;36(2):677-681.

179. Ly K, Essalmani R, Desjardins R, Seidah NG, Day R. An unbiased mass spectrometry approach identifies Glypican-3 as an interactor of proprotein convertase subtilisin/Kexin type 9 (PCSK9) and low density lipoprotein receptor (LDLR) in hepatocellular carcinoma cells. Journal of Biological Chemistry. 2016;291(47):24676-24687. doi:1074/jbc.M116.746883

180. Wang Q, Lu J, Yang C, Wang X, Cheng L, Hu G, Sun Y, Zhang X, Wu M, Liu Z. CASK and its target gene Reelin were co-upregulated in human esophageal carcinoma. Cancer letters. 2002;179(1):71-77. doi:1016/s0304-3835(01)00846-1

181. Sarlos DP, Yusenko MV, Peterfi L, Szanto A, Kovacs G. Dual role of KRT17: development of papillary renal cell tumor and progression of conventional renal cell carcinoma. Journal of Cancer. 2019;10(21):5124-5129. doi:7150/jca.32579

182. Zhang B, Wang J, Huang Z, Wei P, Liu Y, Hao J, Zhao L, Zhang F, Tu Y, Wei T. Aberrantly upregulated TRAP1 is required for tumorigenesis of breast cancer. Oncotarget. 2015;6(42):44495-44508. doi:18632/oncotarget.6252

183. Qin Y, Fu M, Takahashi M, Iwanami A, Kuga D, Rao RG, Sudhakar D, Huang T, Kiyohara M, Torres K et al. Epithelial membrane protein-2 (EMP2) activates Src protein and is a novel therapeutic target for glioblastoma. Journal of Biological Chemistry. 2014;289(20):13974-13985. doi:1074/jbc.M113.543728

184. Wu X, Deng F, Li Y, Daniels G, Du X, Ren Q, Wang J, Wang LH, Yang Y, Zhang V et al. ACSL4 promotes prostate cancer growth, invasion and hormonal resistance. Oncotarget. 2015;6(42):44849-44863. doi:18632/oncotarget.6438

185. Agarwal D, Goodison S, Nicholson B, Tarin D, Urquidi V. Expression of matrix metalloproteinase 8 (MMP-8) and tyrosinase-related protein-1 (TYRP-1) correlates with the absence of metastasis in an isogenic human breast cancer model. Differentiation. 2003;71(2):114-125. doi:1046/j.14320436.2003.710202.x

186. Niu H, Zhou W, Xu Y, Yin Z, Shen W, Ye Z, Liu Y, Chen Y, Yang S, Xiang R et al. Silencing PPA1 inhibits human epithelial ovarian cancer metastasis by suppressing the Wnt/ $\beta$-catenin signaling pathway. Oncotarget. 2017;8(44):76266-76278. doi:18632/oncotarget.19346 
187. Fan X, Zhao Y. miR-451a inhibits cancer growth, epithelial-mesenchymal transition and induces apoptosis in papillary thyroid cancer by targeting PSMB8. J Cell Mol Med. 2019. doi:1111/jcmm.14673

188. Moser C, Ruemmele P, Gehmert S, Schenk H, Kreutz MP, Mycielska ME, Hackl C, Kroemer A, Schnitzbauer AA, Stoeltzing $O$ et al. STAT5b as molecular target in pancreatic cancer-inhibition of tumor growth, angiogenesis, and metastases. Neoplasia. 2012;14(10):915-925. doi:1593/neo.12878

189. Lau WM, Doucet M, Stadel R, Huang D, Weber KL, Kominsky SL. Enpp1: a potential facilitator of breast cancer bone metastasis. PLoS One. 2013;8(7):e66752. doi:1371/journal.pone.0066752

190. Ye Y, Yin M, Huang B, Wang Y, Li X, Lou G. CLIC1 a novel biomarker of intraperitoneal metastasis in serous epithelial ovarian cancer. Tumor Biology. 2015;36(6):4175-4179. doi:1007/s13277-015-30528

191. Chen B, Zeng X, He Y, Wang X, Liang Z, Liu J, Zhang P, Zhu H, Xu N, Liang S. STC2 promotes the epithelial-mesenchymal transition of colorectal cancer cells through AKT-ERK signaling pathways. Oncotarget. 2016;7(44):71400-71416. doi:18632/oncotarget.12147

192. Koie T, Ohyama C, Mikami J, Iwamura H, Fujita N, Sato T, Kojima Y, Fukushi K, Yamamoto H, Imai A et al. Preoperative butyrylcholinesterase level as an independent predictor of overall survival in clear cell renal cell carcinoma patients treated with nephrectomy. The Scientific World Journal. 2014;2014. doi:1155/2014/948305

193. Zhu Y, Luo G, Jiang B, Yu M, Feng Y, Wang M, Xu N, Zhang X. Apolipoprotein M promotes proliferation and invasion in non-small cell lung cancers via upregulating S1PR1 and activating the ERK1/2 and PI3K/AKT signaling pathways. Biochemical and biophysical research communications. 2018;501(2):520-526. doi:1016/j.bbrc.2018.05.029

194. Takaha N, Sowa Y, Takeuchi I, Hongo F, Kawauchi A, Miki T. Expression and role of HMGA1 in renal cell carcinoma. The Journal of urology. 2012;187(6):2215-2222. doi:1016/j.juro.2012.01.069

195. Park JK, Park SH, So K, Bae IH, Yoo YD, Um HD. ICAM-3 enhances the migratory and invasive potential of human non-small cell lung cancer cells by inducing MMP-2 and MMP-9 via Akt and CREB. International journal of oncology. 2010;36(1):181-192.

196. Liang Y, Luo H, Zhang H, Dong Y, Bao Y. Oncogene Delta/Notch-Like EGF-Related Receptor Promotes Cell Proliferation, Invasion, and Migration in Hepatocellular Carcinoma and Predicts a Poor Prognosis. Cancer biotherapy \& radiopharmaceuticals. 2018;33(9):380-386. doi:1089/cbr.2018.2460

197. Liu F, Shangli Z, Hu Z. CAV2 promotes the growth of renal cell carcinoma through the EGFR/PI3K/Akt pathway. OncoTargets and therapy. 2018;11:6209. doi:2147/OTT.S172803

198. Ning XH, Li T, Gong YQ, He Q, Shen QI, Peng SH, Wang JY, Chen JC, Guo YL, Gong K. Association between FBP1 and hypoxia-related gene expression in clear cell renal cell carcinoma. Oncol Lett. 2016;11(6):4095-4098. doi:3892/ol.2016.4504

199. Kaneda A, Kaminishi M, Nakanishi Y, Sugimura T, Ushijima T. Reduced expression of the insulininduced protein 1 and p41 Arp2/3 complex genes in human gastric cancers. Int $\mathrm{J}$ Cancer. 2002;100(1):57-62. doi:1002/ijc.10464 
200. Jin H, Lee K, Kim YH, Oh HK, Maeng YI, Kim TH, Suh DS, Bae J. Scaffold protein FHL2 facilitates MDM2-mediated degradation of IER3 to regulate proliferation of cervical cancer cells. Oncogene. 2016;35(39):5106-5118. doi:1038/onc.2016.54

201. Koster R, Panagiotou OA, Wheeler WA Karlins E, Gastier-Foster JM, Caminada de Toledo SR, Petrilli AS, Flanagan AM, Tirabosco R, Andrulis IL et al. Genome-wide association study identifies the GLDC/IL33 locus associated with survival of osteosarcoma patients. Int J Cancer. 2018;142(8):15941601. doi:1002/ijc.31195

202. Liu Y, Feng X, Lai J, Yi W, Yang J, Du T, Long X, Zhang Y, Xiao Y. A novel role of kynureninase in the growth control of breast cancer cells and its relationships with breast cancer. J Cell Mol Med. 2019;23(10):6700-6707. doi:1111/jcmm.14547

203. Ren P, Zhang JG, Xiu L, Yu ZT. Clinical significance of phospholipase A2 group IIA (PLA2G2A) expression in primary resected esophageal squamous cell carcinoma. Eur Rev Med Pharmacol Sci. 2013;17(6):752-.757.

204. Guo CC, Zhang XL, Yang B, Geng J, Peng B, Zheng JH. Decreased expression of Dkk1 and Dkk3 in human clear cell renal cell carcinoma. Molecular medicine reports. 2014;9(6):2367-2373. doi:3892/mmr.2014.2077

205. Burdelski C, Kleinhans S, Kluth M, Hube-Magg C, Minner S, Koop C, Graefen M, Heinzer H, Tsourlakis MC, Wilczak W, Marx A. Reduced AZGP1 expression is an independent predictor of early PSA recurrence and associated with ERG-fusion positive and PTEN deleted prostate cancers. International journal of cancer. 2016;138(5):1199-1206. doi:1002/ijc.29860

206. Watson JV, Kamkar S, James K, Kowbel D, Andaya A, Paris PL, Simko J, Carroll P, McAlhany S, Rowley D, Collins C. Molecular analysis of WFDC1/ps20 gene in prostate cancer. The Prostate. 2004;61(2):192-199. doi:1002/pros.20100

207. Das R, Gregory PA, Fernandes RC, Denis I, Wang Q, Townley SL, Zhao SG, Hanson AR, Pickering MA, Armstrong HK et al. MicroRNA-194 promotes prostate cancer metastasis by inhibiting SOCS2. Cancer research. 2017;77(4):1021-1034. doi:1158/0008-5472.CAN-16-2529

208. Kocabaş NA, Sardaş S, Cholerton S, Daly AK, Karakaya AE. Cytochrome P450 CYP1B1 and catechol O-methyltransferase (COMT) genetic polymorphisms and breast cancer susceptibility in a Turkish population. Arch Toxicol. 2002 Nov;76(11):643-649. doi:1007/s00204-002-0387-x

209. Cox DG, Pontes C, Guino E, Navarro M, Osorio A, Canzian F, Moreno V. Polymorphisms in prostaglandin synthase 2/cyclooxygenase 2 (PTGS2/COX2) and risk of colorectal cancer. $\mathrm{Br} \mathrm{J}$ Cancer. 2004;91(2):339-343. doi:1038/sj.bjc.6601906

210. Yumrutas O, Oztuzcu S, Büyükhatipoglu H, Bozgeyik I, Bozgeyik E, Igci YZ, Bagis H, Cevik MO, Kalender ME, Eslik $Z$ et al. The role of the UTS2 gene polymorphisms and plasma Urotensin-II levels in breast cancer. Tumor Biology. 2015;36(6):4427-4432. doi:1007/s13277-015-3082-2

211. Zhang J, Fu Y, Chen J, Li Q, Guo H, Yang B. Genetic variant of TMBIM1 is associated with the susceptibility of colorectal cancer in the Chinese population. Clinics and research in hepatology and gastroenterology. 2019;43(3):324-329. doi:1016/j.clinre.2018.10.013 
212. Hodson I, Bock M, Ritz U, Brenner W, Huber C, Seliger B. Analysis of the structural integrity of the TAP2 gene in renal cell carcinoma. International journal of oncology. 2003;23(4):991-999.

213. Li Y, Nie Y, Cao J, Tu S, Lin Y, Du Y, Li Y. G-A variant in miR-200c binding site of EFNA1 alters susceptibility to gastric cancer. Molecular carcinogenesis. 2014;53(3):219-229. doi:1002/mc.21966

214. Chen FD, Chen HH, Ke SC, Zheng LR Zheng XY. SLC27A2 regulates miR-411 to affect chemoresistance in ovarian cancer. Neoplasma. 2018;65(6):915-924. doi:4149/neo_2018_180122N48

215. Wu H, Wang K, Liu W, Hao Q. Recombinant adenovirus-mediated overexpression of PTEN and KRT10 improves cisplatin resistance of ovarian cancer in vitro and in vivo. Genet Mol Res. 2015;14(2):65916597. doi:4238/2015

216. Moelans CB, Verschuur-Maes AH, Van Diest PJ. Frequent promoter hypermethylation of BRCA2, CDH13, MSH6, PAX5, PAX6 and WT1 in ductal carcinoma in situ and invasive breast cancer. The Journal of pathology. 2011;225(2):222-231. doi:1002/path.2930

217. Ohshima J, Haruta M, Arai Y, Kasai F, Fujiwara Y, Ariga T, Okita H, Fukuzawa M, Hata J, Horie H et al. Two candidate tumor suppressor genes, MEOX2 and SOSTDC1, identified in a 7p21 homozygous deletion region in a Wilms tumor. Genes Chromosomes Cancer. 2009;48(12):1037-1050. doi:1002/gcc. 20705

218. Sehic D, Karlsson J, Sandstedt B, Gisselsson D. SIX1 protein expression selectively identifies blastemal elements in Wilms tumor. Pediatr Blood Cancer. 2012;59(1):62-68. doi:1002/pbc.24025

219. Percicote AP, Mardegan GL, Gugelmim ES, loshii SO, Kuczynski AP, Nagashima S, de Noronha L. Tissue expression of retinoic acid receptor alpha and CRABP2 in metastatic nephroblastomas. Diagn Pathol. 2018;13(1):9. doi:1186/s13000-018-0686-z

220. Yoo KH Park YK, Kim HS, Jung WW, Chang SG. Epigenetic inactivation of HOXA5 and MSH2 gene in clear cell renal cell carcinoma. Pathol Int. 2010;60(10):661-666. doi:1111/j.1440-1827.2010.02578.x

221. Luo J, Wang W, Tang Y, Zhou D, Gao Y, Zhang Q, Zhou X, Zhu H, Xing L, Yu J. mRNA and methylation profiling of radioresistant esophageal cancer cells: the involvement of Sall2 in acquired aggressive phenotypes. J Cancer. 2017;8(4):646-656. doi:7150/jca.15652

222. Gooskens SL, Gadd S, Guidry Auvil JM, Gerhard DS, Khan J, Patidar R, Meerzaman D, Chen QR, Hsu $\mathrm{CH}$, Yan $\mathrm{C}$ et al. TCF21 hypermethylation in genetically quiescent clear cell sarcoma of the kidney. Oncotarget. 2015;6(18):15828-15841. doi:18632/oncotarget.4682

223. Cheng SJ, Chang CF, Ko HH, Lee JJ, Chen HM, Wang HJ, Lin HS, Chiang CP. Hypermethylated ZNF582 and PAX1 genes in mouth rinse samples as biomarkers for oral dysplasia and oral cancer detection. Head Neck. 2018;40(2):355-368. doi:1002/hed.24958

224. Brebi P, Maldonado L, Noordhuis MG, Ili C, Leal P, Garcia P, Brait M, Ribas J, Michailidi C, Perez J et al. Genome-wide methylation profiling reveals Zinc finger protein 516 (ZNF516) and FK-506-binding protein 6 (FKBP6) promoters frequently methylated in cervical neoplasia, associated with HPV status and ethnicity in a Chilean population. Epigenetics. 2014;9(2):308-317. doi:4161/epi.27120

225. Kim J, Min SY, Lee HE, Kim WH. Aberrant DNA methylation and tumor suppressive activity of the EBF3 gene in gastric carcinoma. Int J Cancer. 2012;130(4):817-826. doi:1002/ijc.26038 
226. Li Y, Yang Q, Guan H, Shi B, Ji M, Hou P. ZNF677 Suppresses Akt Phosphorylation and Tumorigenesis in Thyroid Cancer. Cancer Res. 2018;78(18):5216-5228. doi:1158/0008-5472.CAN-18-0003

227. Vider BZ, Zimber A, Chastre E, Gespach C, Halperin M, Mashiah P, Yaniv A, Gazit A. Deregulated expression of homeobox-containing genes, $\mathrm{HOXB} 6, \mathrm{~B} 8, \mathrm{C} 8, \mathrm{C} 9$, and $\mathrm{Cdx}-1$, in human colon cancer cell lines. Biochem Biophys Res Commun. 2000;272(2):513-518. doi:1006/bbrc.2000.2804

228. Li Y, Huang Y, Qi Z, Sun T, Zhou Y. MiR-338-5p Promotes Glioma Cell Invasion by Regulating TSHZ3 and MMP2. Cell Mol Neurobiol. 2018;38(3):669-677. doi:1007/s10571-017-0525-x

229. Suzuki H, Ouchida M, Yamamoto H, Yano M, Toyooka S, Aoe M, Shimizu N, Date H, Shimizu K. Decreased expression of the SIN3A gene, a candidate tumor suppressor located the prevalent allelic loss region 15q23 in non-small cell lung cancer. Lung Cancer. 2008;59(1):24-31. doi:1016/j.lungcan.2007.08.002

230. Henrich KO, Bauer T, Schulte J, Ehemann V, Deubzer H, Gogolin S, Muth D, Fischer M, Benner A, König $\mathrm{R}$ et al. CAMTA1, a 1 p36 tumor suppressor candidate, inhibits growth and activates differentiation programs in neuroblastoma cells. Cancer Res. 2011;71(8):3142-3151. doi:1158/0008-5472.CAN-103014

231. Shulewitz M, Soloviev I, Wu T, Koeppen H, Polakis P, Sakanaka C. Repressor roles for TCF-4 and Sfrp1 in Wnt signaling in breast cancer. Oncogene. 2006;25(31):4361-4369. doi:1038/sj.onc.1209470

232. Bhanvadia RR, VanOpstall C, Brechka H, Barashi NS, Gillard M, McAuley EM, Vasquez JM, Paner G, Chan WC, Andrade $\mathrm{J}$ et al. MEIS1 and MEIS2 Expression and Prostate Cancer Progression: A Role For HOXB13 Binding Partners in Metastatic Disease. Clin Cancer Res. 2018;24(15):3668-3680. doi:1158/1078-0432.CCR-17-3673

233. Zheng J, Ge P, Liu X, Wei J, Wu G, Li X. MiR-136 inhibits gastric cancer-specific peritoneal metastasis by targeting HOXC10. Tumour Biol. 2017;39(6):1010428317706207. doi:1177/1010428317706207

234. Stenzinger A, von Winterfeld M, Rabien A, Warth A, Kamphues C, Dietel M, Weichert W, Klauschen F, Wittschieber D. Reversion-inducing cysteine-rich protein with Kazal motif (RECK) expression: an independent prognostic marker of survival in colorectal cancer. Hum Pathol. 2012;43(8):1314-1321. doi:1016/j.humpath.2011.10.012

235. Peng Y, Liu YM, Li LC, Wang LL, Wu XL. MicroRNA-338 inhibits growth, invasion and metastasis of gastric cancer by targeting NRP1 expression. PLoS One. 2014;9(4):e94422. doi:1371/journal.pone.0094422

236. Sasahira T, Nishiguchi Y, Fujiwara R, Kurihara M, Kirita T, Bosserhoff AK, Kuniyasu H. Storkhead box 2 and melanoma inhibitory activity promote oral squamous cell carcinoma progression. Oncotarget. 2016;7(18):26751-26764. doi:18632/oncotarget.8495

237. Feng Q, Wu X, Li F, Ning B, Lu X, Zhang Y, Pan Y, Guan W. miR-27b inhibits gastric cancer metastasis by targeting NR2F2. Protein Cell. 2017;8(2):114-122. doi:1007/s13238-016-0340-z

238. Feigin ME, Xue B, Hammell MC, Muthuswamy SK. G-protein-coupled receptor GPR161 is overexpressed in breast cancer and is a promoter of cell proliferation and invasion. Proc Natl Acad Sci U S A. 2014;111(11):4191-4196. doi:1073/pnas.1320239111 
239. Zhu X, Wei L, Bai Y, Wu S, Han S. FoxC1 promotes epithelial-mesenchymal transition through PBX1 dependent transactivation of ZEB2 in esophageal cancer. Am J Cancer Res. 2017;7(8):1642-1653.

240. Zhao L, Zhang Y, Liu J, Yin W, Jin D, Wang D, Zhang W. miR-185 Inhibits the Proliferation and Invasion of Non-Small Cell Lung Cancer by Targeting KLF7. Oncol Res. 2019;27(9):1015-1023. doi:3727/096504018X15247341491655

241. Shu L, Zhang Z, Cai Y. MicroRNA-204 inhibits cell migration and invasion in human cervical cancer by regulating transcription factor 12. Oncol Lett. 2018;15(1):161-166. doi:3892/ol.2017.7343

242. Wu H, Liu X, Gong P, Song W, Zhou M, Li Y, Zhao Z, Fan H.Elevated TFAP4 regulates IncRNA TRERNA1 to promote cell migration and invasion in gastric cancer. Oncol Rep. 2018;40(2):923-931. doi:3892/or.2018.6466

243. Jia C, Zhang Y, Xie Y, Ren Y, Zhang H, Zhou Y, Gao N, Ding S, Han S. miR-200a-3p plays tumor suppressor roles in gastric cancer cells by targeting KLF12. Artif Cells Nanomed Biotechnol. 2019;47(1):3697-3703. doi:1080/21691401.2019.1594857

244. Liu J, Jiang J, Hui X, Wang W, Fang D, Ding L. Mir-758-5p Suppresses Glioblastoma Proliferation, Migration and Invasion by Targeting ZBTB20. Cell Physiol Biochem. 2018;48(5):2074-2083. doi:1159/000492545

245. Tsimafeyeu I, Demidov L, Stepanova E, Wynn N, Ta H. Overexpression of fibroblast growth factor receptors FGFR1 and FGFR2 in renal cell carcinoma. Scand J Urol Nephrol. 2011;45(3):190-195. doi:3109/00365599.2011.552436

246. Vanderleede B, Opdenoordt T, Vandenbrink C, Ebert T, Vandersaag P. Implication of retinoic Acid receptor-Beta in renal-cell carcinoma. Int J Oncol. 1995;6(2):391-400. doi:3892/ijo.6.2.391

247. Kataoka H, Tanaka M, Kanamori M, Yoshii S, Ihara M, Wang YJ, Song JP, Li ZY, Arai H, Otsuki Y et al. Expression profile of EFNB1, EFNB2, two ligands of EPHB2 in human gastric cancer. J Cancer Res Clin Oncol. 2002 Jul;128(7):343-348. doi:1007/s00432-002-0355-0

248. Tian C, Huang D, Yu Y, Zhang J, Fang Q, Xie C. ABCG1 as a potential oncogene in lung cancer. Exp Ther Med. 2017;13(6):3189-3194. doi:3892/etm.2017.4393

249. Han Y, Ru GQ, Mou X, Wang HJ, Ma Y, He XL, Yan Z, Huang D. AUTS2 is a potential therapeutic target for pancreatic cancer patients with liver metastases. Med Hypotheses. 2015;85(2):203-206. doi:1016/j.mehy.2015.04.029

250. Jin H, Sun W, Zhang Y, Yan H, Liufu H, Wang S, Chen C, Gu J, Hua X, Zhou L et al. MicroRNA-411 Downregulation Enhances Tumor Growth by Upregulating MLLT11 Expression in Human Bladder Cancer. Mol Ther Nucleic Acids. 2018;11:312-322. doi:1016/j.omtn.2018.03.003

251. Rami F, Baradaran A, Kahnamooi MM, Salehi M. Alteration of GLIS3 gene expression pattern in patients with breast cancer. Adv Biomed Res. 2016;5:44. doi:4103/2277-9175.178803

252. Zhang C, Liu J, Zhang Y, Luo C, Zhu T, Zhang R, Yao R. LINC01342 promotes the progression of ovarian cancer by absorbing microRNA-30c-2-3p to upregulate HIF3A. J Cell Physiol. 2019. doi:1002/jcp.29289 
253. Takai N, Miyazaki T, Nishida M, Shang S, Nasu K, Miyakawa I. Clinical relevance of Elf-1 overexpression in endometrial carcinoma. Gynecol Oncol. 2003;89(3):408-413. doi:1016/s00908258(03)00131-8

254. Rae FK, Hooper JD, Nicol DL, Clements JA. Characterization of a novel gene, STAG1/PMEPA1, upregulated in renal cell carcinoma and other solid tumors. Mol Carcinog. 2001;32(1):44-53. doi:1002/mc.1063

255. Khaled WT, Choon Lee S, Stingl J, Chen X, Raza Ali H, Rueda OM, Hadi F, Wang J, Yu Y, Chin SF et al. BCL11A is a triple-negative breast cancer gene with critical functions in stem and progenitor cells. Nat Commun. 2015;6:5987. doi:1038/ncomms6987

256. Meijer D, Jansen MP, Look MP, Ruigrok-Ritstier K, van Staveren IL, Sieuwerts AM, van Agthoven T, Foekens JA, Dorssers LC, Berns EM. TSC22D1 and PSAP predict clinical outcome of tamoxifen treatment in patients with recurrent breast cancer. Breast Cancer Res Treat. 2009;113(2):253-60. doi:1007/s10549-008-9934-3

257. Sohn EJ, Jung DB, Lee H, Han I, Lee J, Lee H, Kim SH. CNOT2 promotes proliferation and angiogenesis via VEGF signaling in MDA-MB-231 breast cancer cells. Cancer Lett. 2018;431:245-246. doi:1016/j.canlet.2018.05.002

258. Shi Y, Zhao Y, Zhang Y, AiErken, Shao N, Ye R, Lin Y4 Wang S. AFF3 upregulation mediates tamoxifen resistance in breast cancers. J Exp Clin Cancer Res. 2018;37(1):254. doi:1186/s13046018-0928-7

259. Lu T, Li L, Zhu J, Liu J, Lin A, Fu W, Liu G, Xia H, Zhang T, He J. AURKA rs8173 G> C Polymorphism Decreases Wilms Tumor Risk in Chinese Children. Journal of oncology. 2019;2019:9074908. doi:1155/2019/9074908

260. Yu L, Liu X, Cui K, Di Y, Xin L, Sun X, Zhang W, Yang X, Wei M, Yao Z et al. SND1 acts downstream of TGF $\beta 1$ and upstream of Smurf1 to promote breast cancer metastasis. Cancer research. 2015;75(7):1275-1286. doi:1158/0008-5472.CAN-14-2387

261. Lou JC, Lan YL, Gao JX, Ma BB, Yang T, Yuan ZB, Zhang HQ, Zhu TZ, Pan N, Leng S et al. Silencing NUDT21 attenuates the mesenchymal identity of glioblastoma cells via the NF-KB pathway. Frontiers in molecular neuroscience. 2017;10:420. doi:3389/fnmol.2017.00420

262. Zhang Z, Zhang G, Kong C. FOXM1 participates in PLK1-regulated cell cycle progression in renal cell cancer cells. Oncology letters. 2016;11(4):2685-2691. doi:3892/ol.2016.4228

263. Wang W, Yang Y, Chen X, Shao S, Hu S, Zhang T. MAGI1 mediates tumor metastasis through cMyb/miR-520h/MAGI1 signaling pathway in renal cell carcinoma. Apoptosis. 2019;24(11-12):837848. doi:1007/s10495-019-01562-8

264. Su Y, Xiong J, Hu J, Wei X, Zhang X, Rao L. MicroRNA-140-5p targets insulin like growth factor 2 mRNA binding protein 1 (IGF2BP1) to suppress cervical cancer growth and metastasis. Oncotarget. 2016;7(42):68397-68411. doi:18632/oncotarget.11722

265. Arai T, Kojima S, Yamada Y, Sugawara S, Kato M, Yamazaki K, Naya Y, Ichikawa T, Seki N. Pirin: a potential novel therapeutic target for castration-resistant prostate cancer regulated by miR-455- 
Molecular oncology. 2019;13(2):322-337. doi:10.1002/1878-0261.12405

266. Elsheikh S, Green AR, Aleskandarany MA, Grainge M, Paish CE, Lambros MB, Reis-Filho JS, Ellis IO. CCND1 amplification and cyclin D1 expression in breast cancer and their relation with proteomic subgroups and patient outcome. Breast cancer research and treatment. 2008;109(2):325-335. doi:1007/s10549-007-9659-8

267. Bissig H, Staehelin F, Tolnay M, Avoledo P, Richter J, Betts D, Bruder E, Kühne T. Co-occurrence of neuroblastoma and nephroblastoma in an infant with Fanconi's anemia. Human pathology. 2002;33(10):1047-1051. doi:1053/hupa.2002.128062

268. Flores-Pérez A, Marchat LA, Rodríguez-Cuevas S, Bautista VP, Fuentes-Mera L, Romero-Zamora D, Maciel-Dominguez A, de la Cruz OH, Fonseca-Sánchez M, Ruíz-García E et al. Suppression of cell migration is promoted by miR-944 through targeting of SIAH1 and PTP4A1 in breast cancer cells. BMC cancer. 2016;16(1):379. doi:1186/s12885-016-2470-3

269. Wang N, Zhan T, Ke T, Huang X, Ke D, Wang Q, Li H. Increased expression of RRM2 by human papillomavirus E7 oncoprotein promotes angiogenesis in cervical cancer. British journal of cancer. 2014;110(4):1034-1044. doi:1038/bjc.2013.817

270. Ma F, Bi L, Yang G, Zhang M, Liu C, Zhao Y, Wang Y, Wang J, Bai Y, Zhang Y. ZNF703 promotes tumor cell proliferation and invasion and predicts poor prognosis in patients with colorectal cancer. Oncology reports. 2014;32(3):1071-1077. doi:3892/or.2014.3313

271. Yang F, Zhou X, Miao X, Zhang T, Hang X, Tie R, Liu N, Tian F, Wang F, Yuan J. MAGEC2, an epithelialmesenchymal transition inducer, is associated with breast cancer metastasis. Breast cancer research and treatment. 2014;145(1):23-32. doi:1007/s10549-014-2915-9

272. Ma HW, Xie M, Sun M, Chen TY, Jin RR, Ma TS, Chen QN, Zhang EB, He XZ, De W, et al. The pseudogene derived long noncoding RNA DUXAP8 promotes gastric cancer cell proliferation and migration via epigenetically silencing PLEKHO1 expression. Oncotarget. 2017;8(32):52211-52224. doi:18632/oncotarget.11075

\section{Tables}

Due to technical limitations, Tables 1-8 are only available as a download in the supplementary files section.

\section{Figures}


A

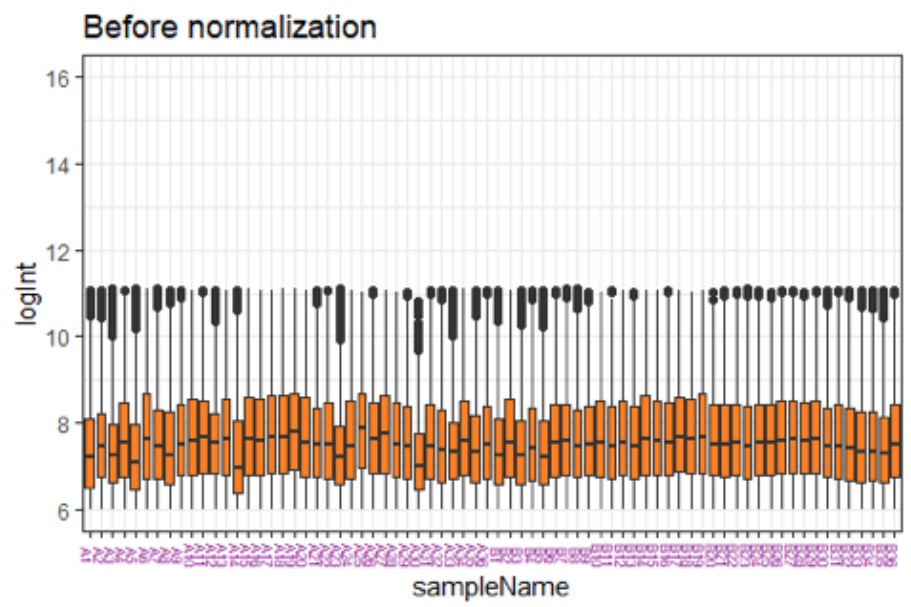

B

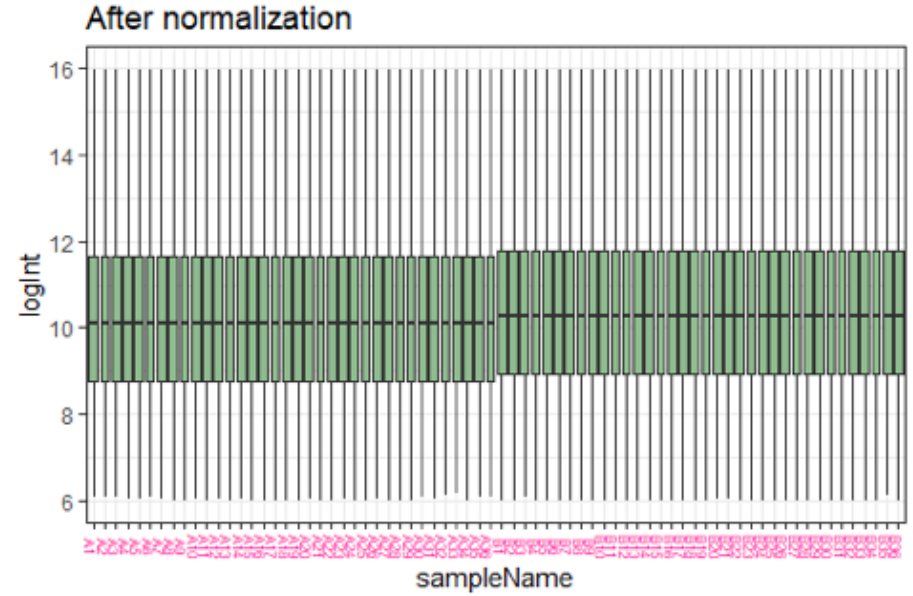

\section{Figure 1}

Box plots of the gene expression data before normalization (A) and after normalization (B). Horizontal axis represents the sample symbol and the vertical axis represents the gene expression values. The black line in the box plot represents the median value of gene expression. (A1 - A36 = normal tissues samples; B1 - B36 = WT tissues samples)

\section{Volcano plot}

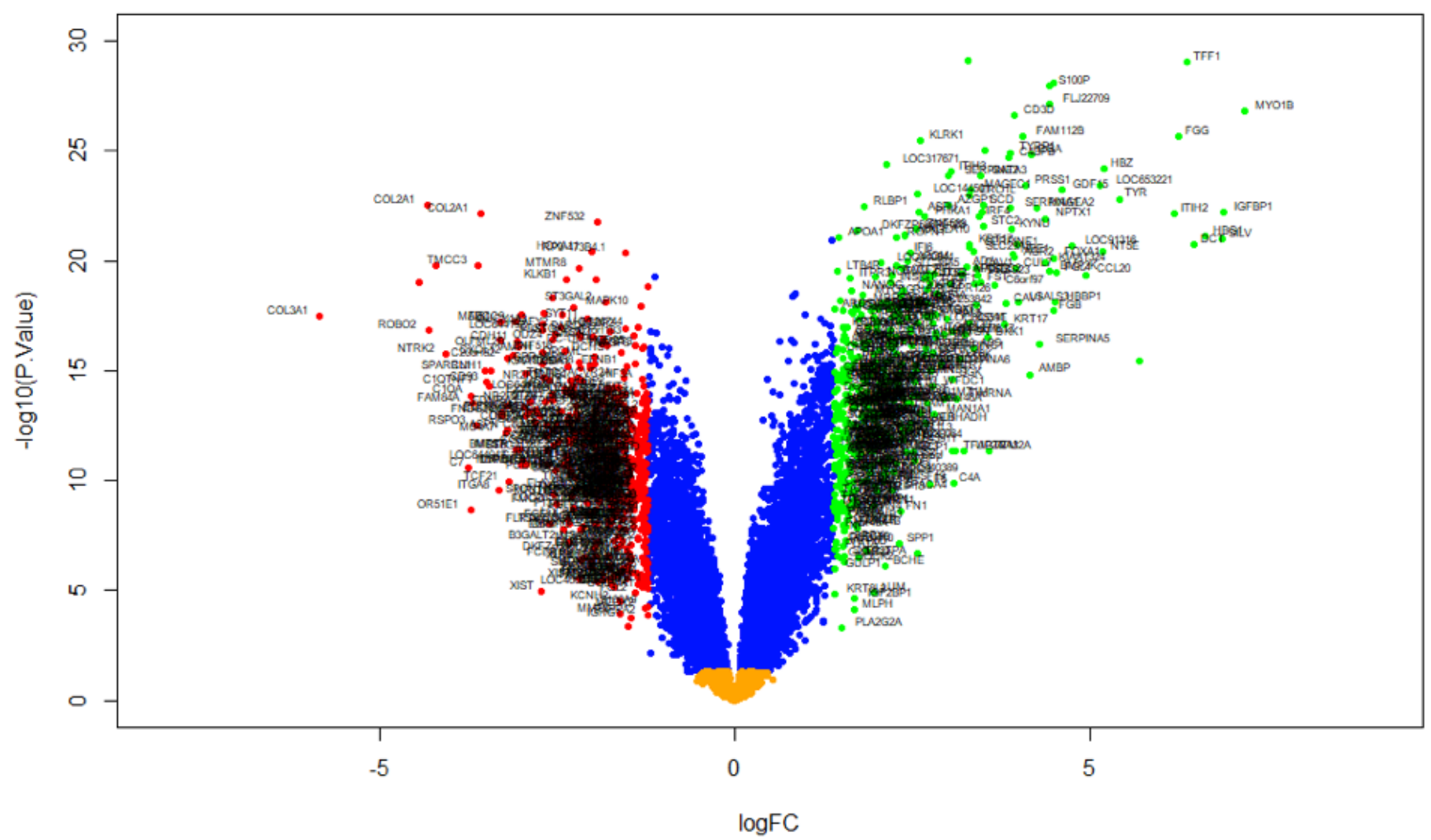

Figure 2 
Volcano plot of differentially expressed genes. Genes with a significant change of more than two-fold were selected. Green dot significant up regulated genes and red dot significant down regulated genes.
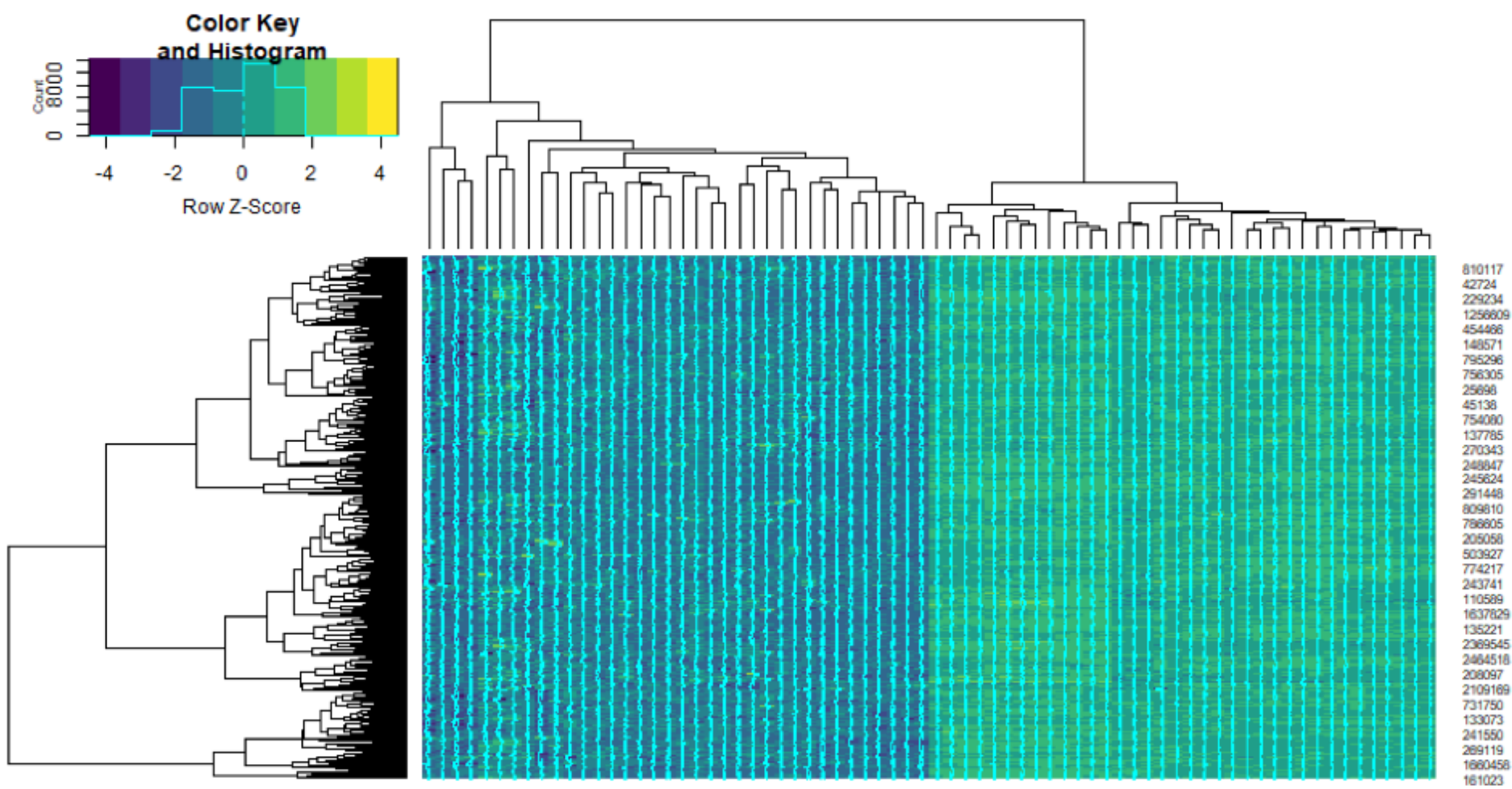

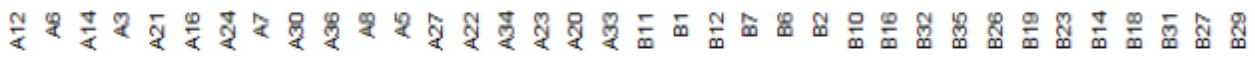

\section{Figure 3}

Heat map of up regulated differentially expressed genes. Legend on the top left indicate log fold change of genes. (A1 - A36 = normal tissues samples; B1 - B36 = WT tissues samples) 

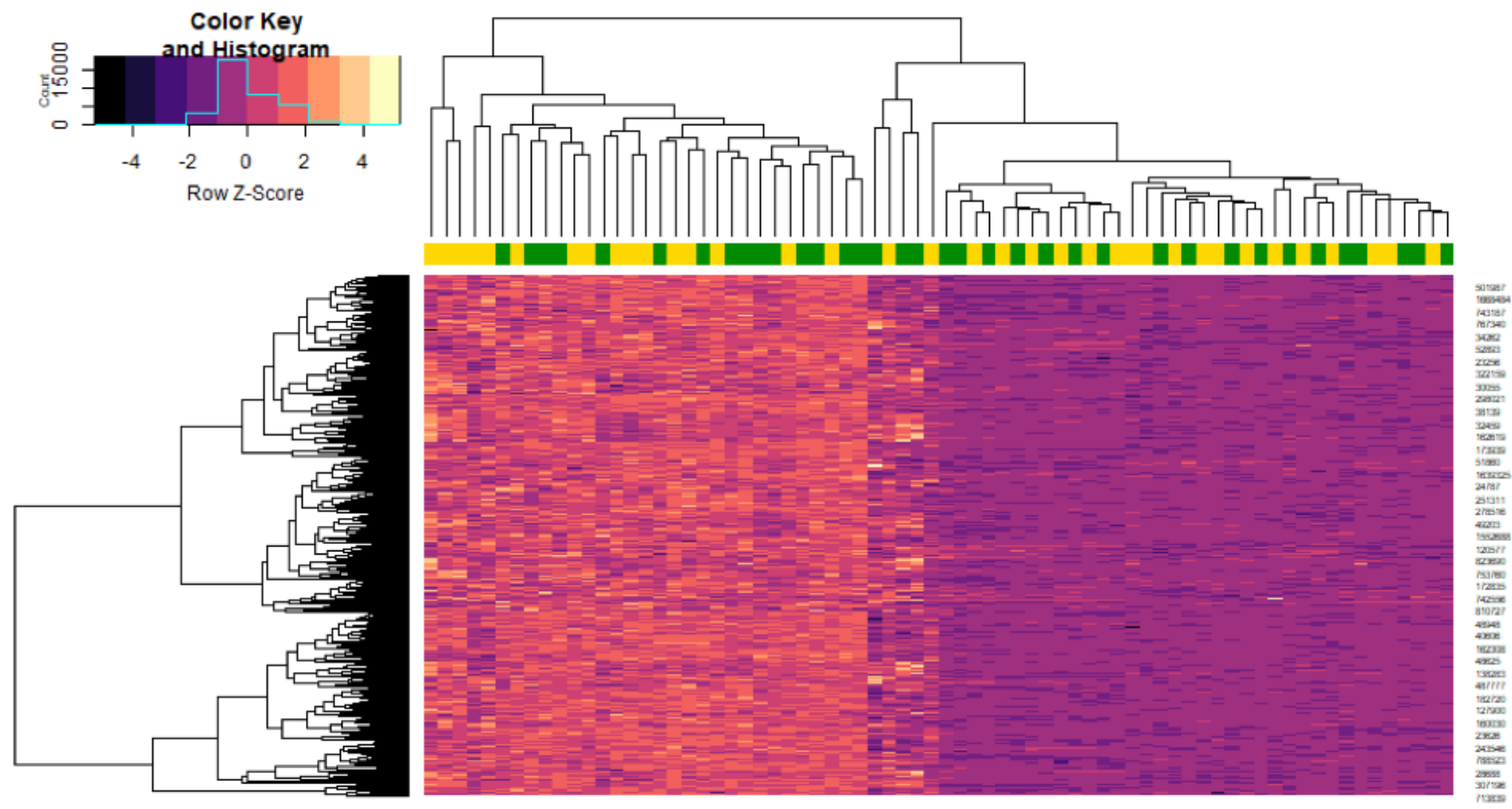

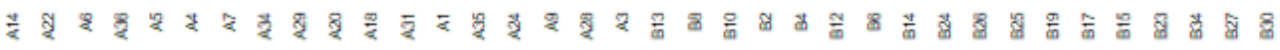

\section{Figure 4}

Heat map of down regulated differentially expressed genes. Legend on the top left indicate log fold change of genes. (A1 - A36 = normal tissues samples; B1 - B36 = WT tissues samples)

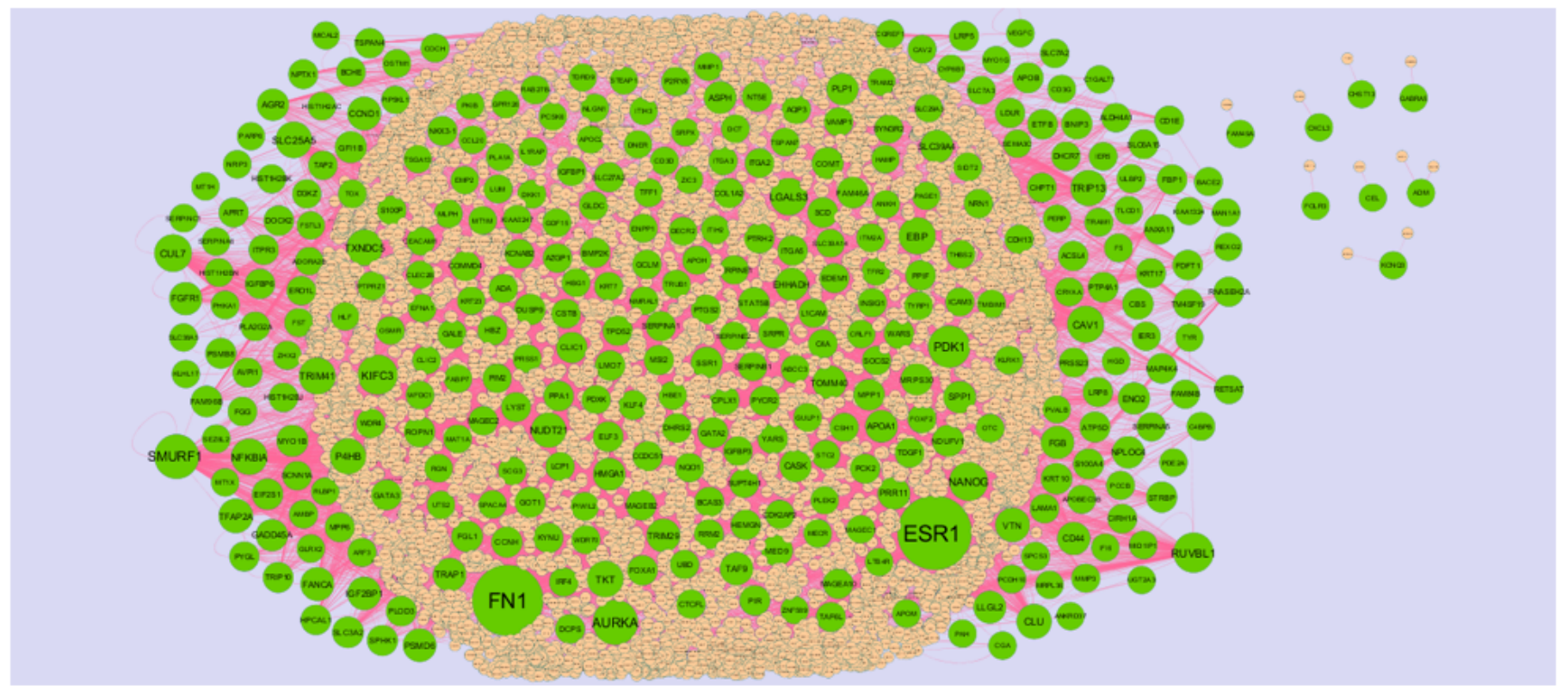

\section{Figure 5}

Protein-protein interaction network of up regulated genes. Green nodes denotes up regulated genes. 


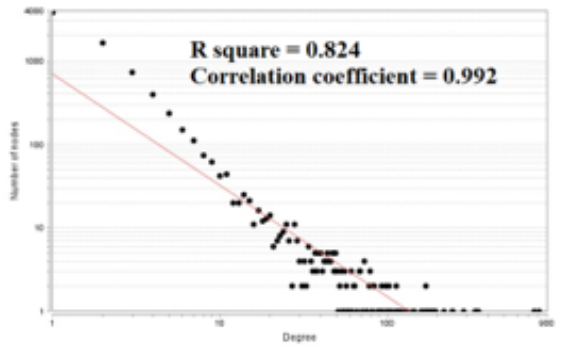

D

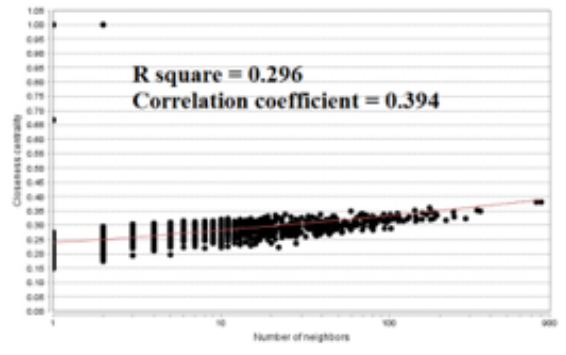

B

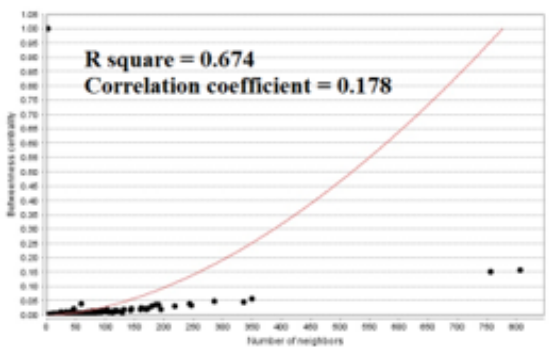

$\mathbf{E}$

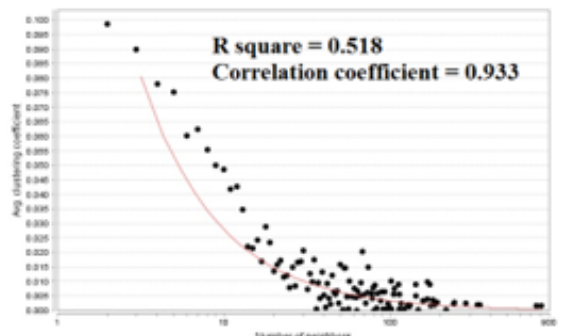

\section{Figure 6}

Regression diagrams for up regulated genes. (A- Node degree; B- Betweenness centrality; C- Stress centrality ; D-Closeness centrality; E- Clustering coefficient)

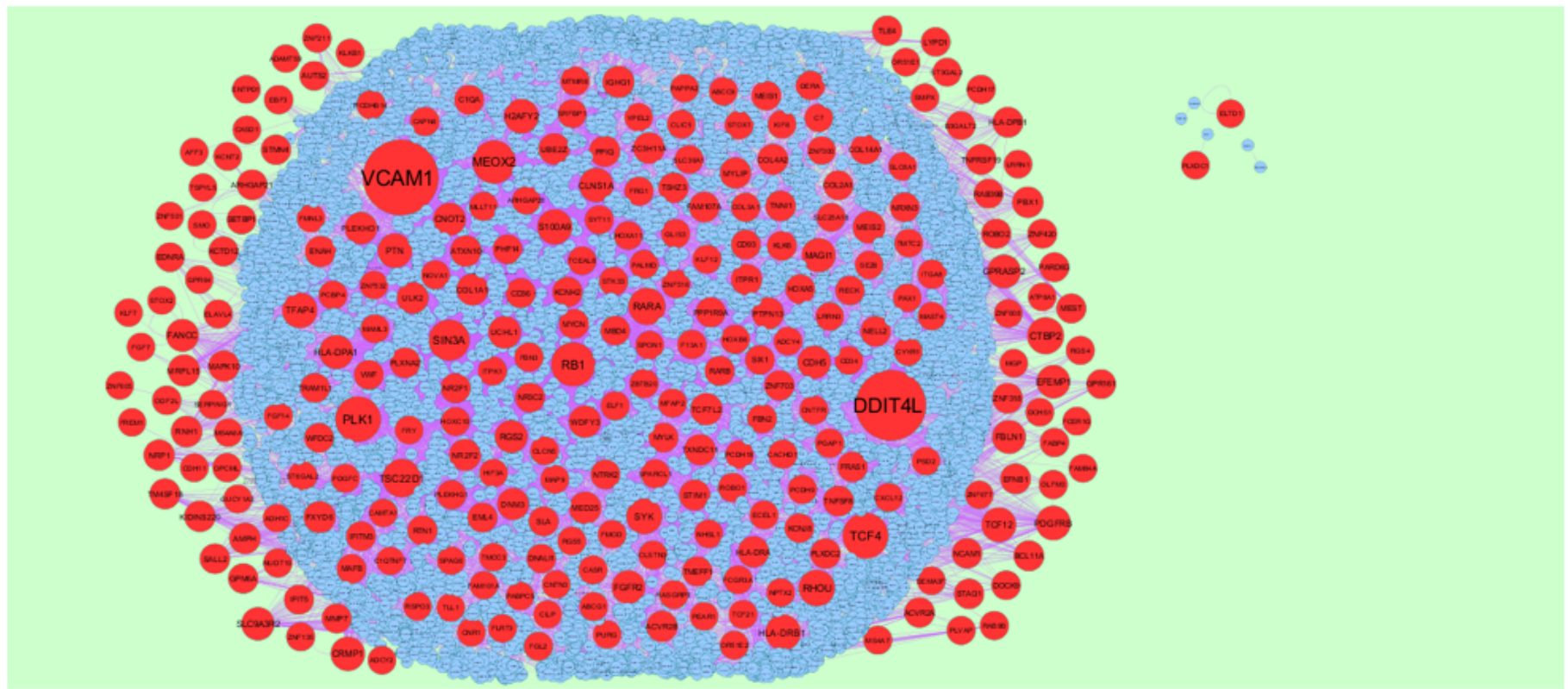

Figure 7

Protein-protein interaction network of down regulated genes. Red nodes denotes down regulated genes. 

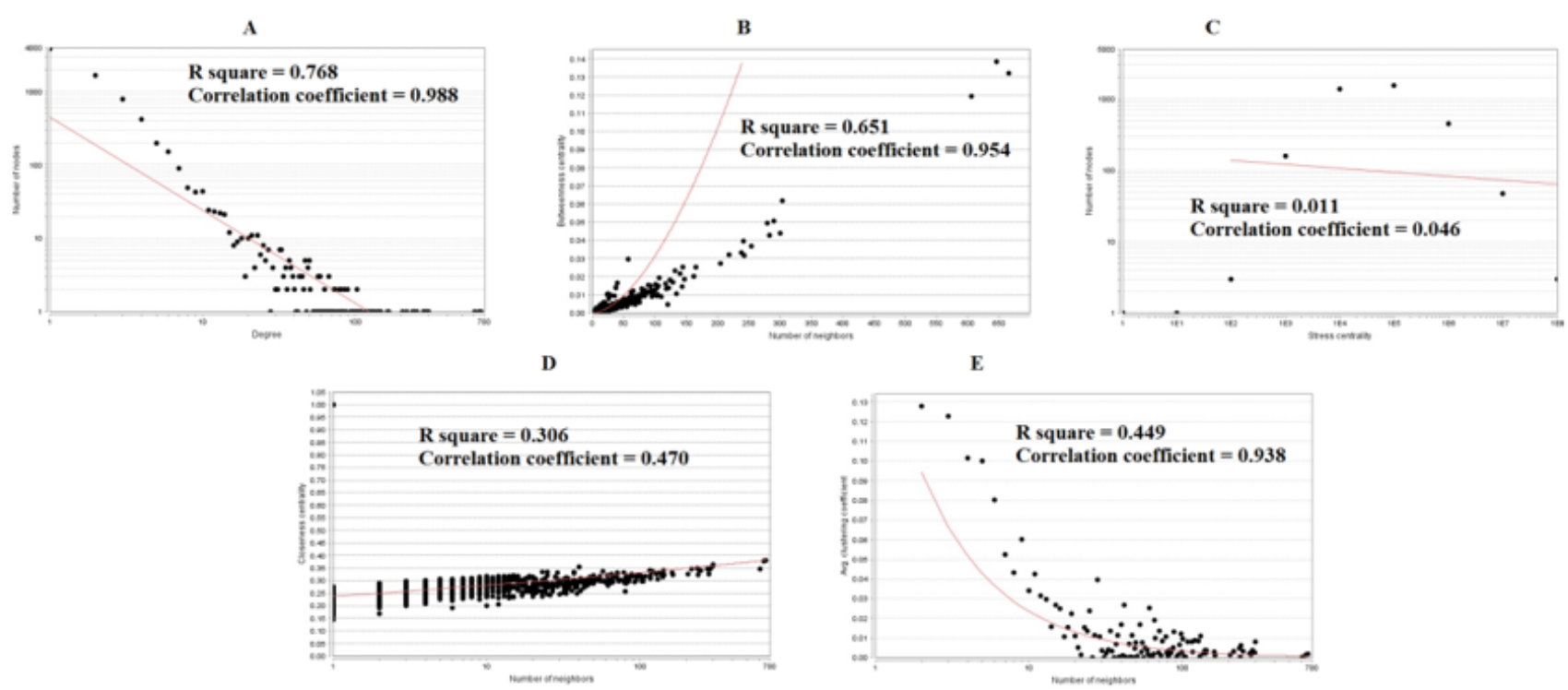

Figure 8

Regression diagrams for down regulated genes. (A-Node degree; B-Betweenness centrality; C- Stress centrality ; D-Closeness centrality; E- Clustering coefficient)

\section{Module 14}

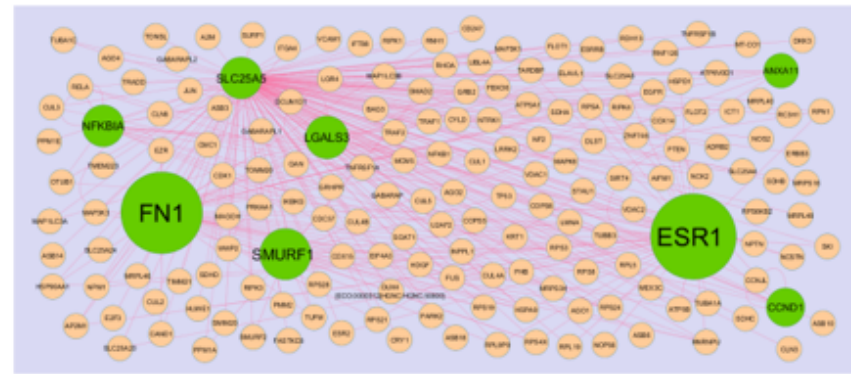

Module 39

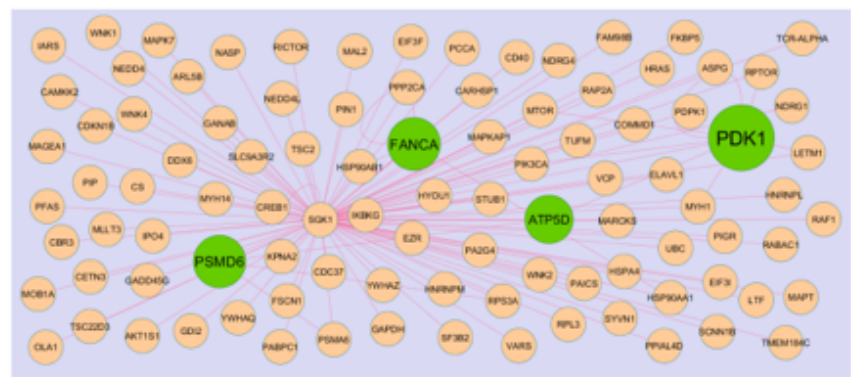

Module 24

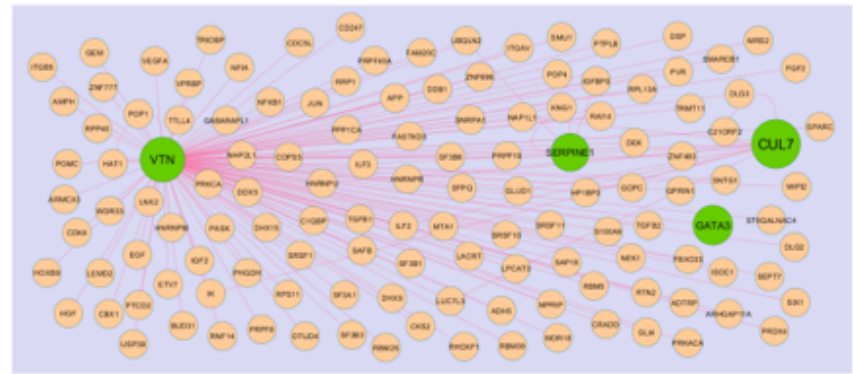

Module 40

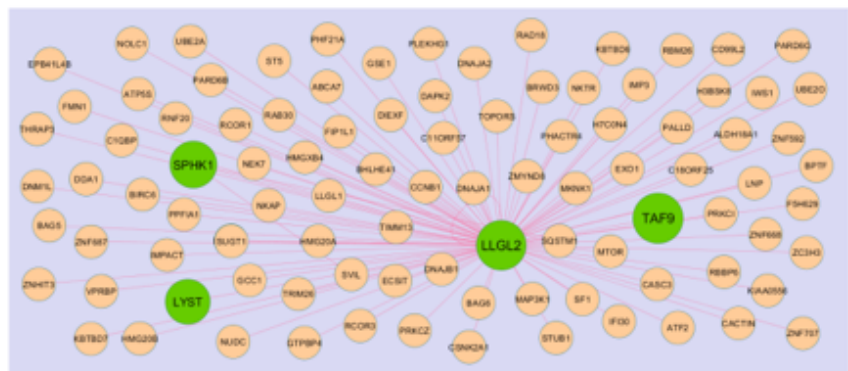

\section{Figure 9}

Modules in PPI network. The green nodes denote the up regulated genes. 


\section{Module 17}

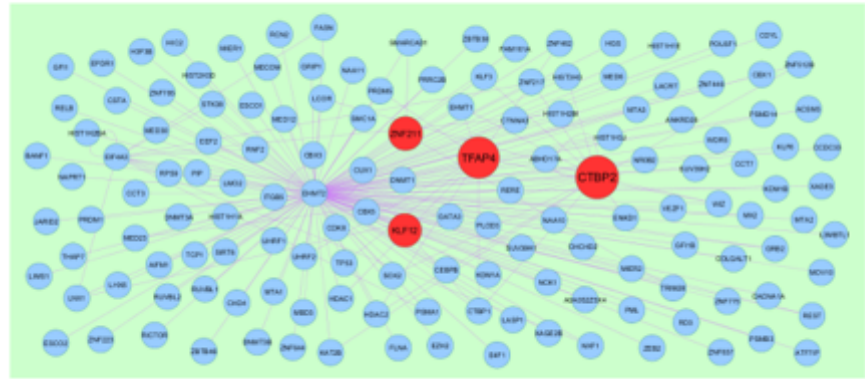

\section{Module 34}

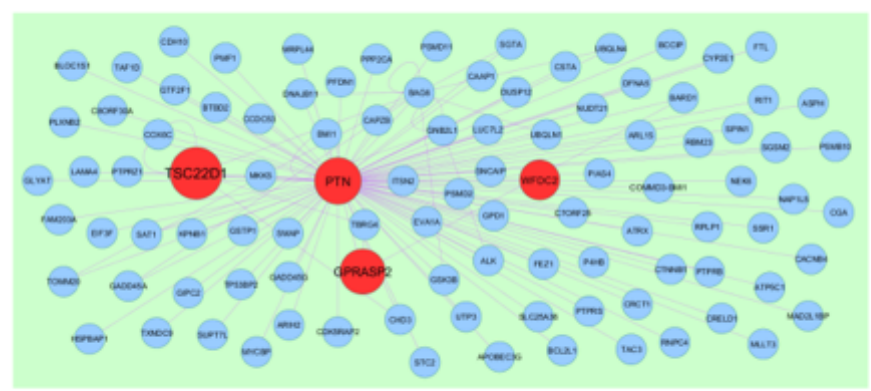

\section{Module 24}

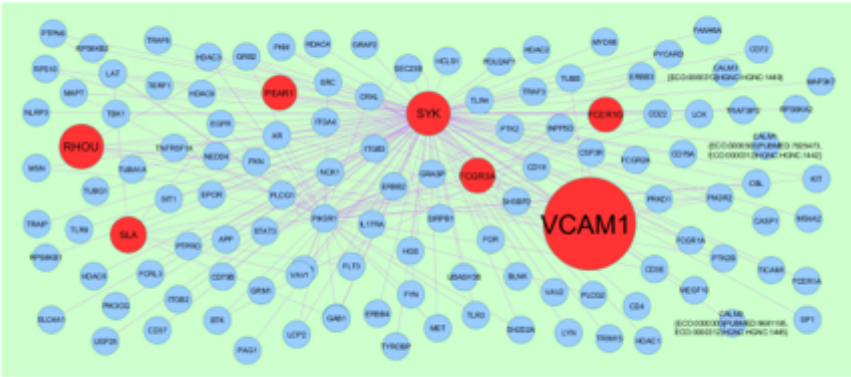

\section{Module 40}

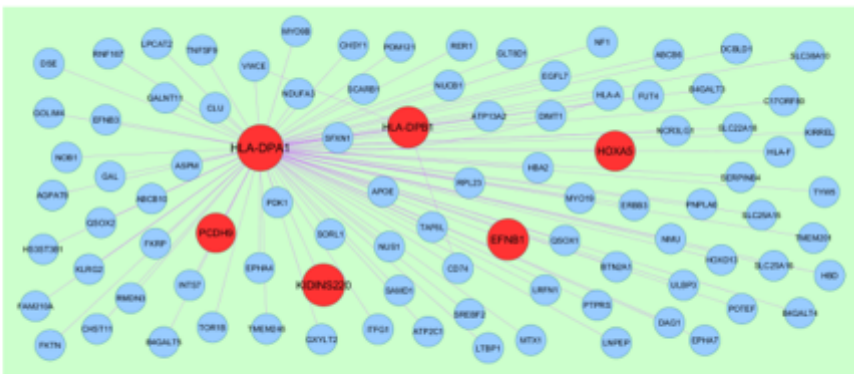

\section{Figure 10}

Modules in PPI network. The red nodes denote the down regulated genes.

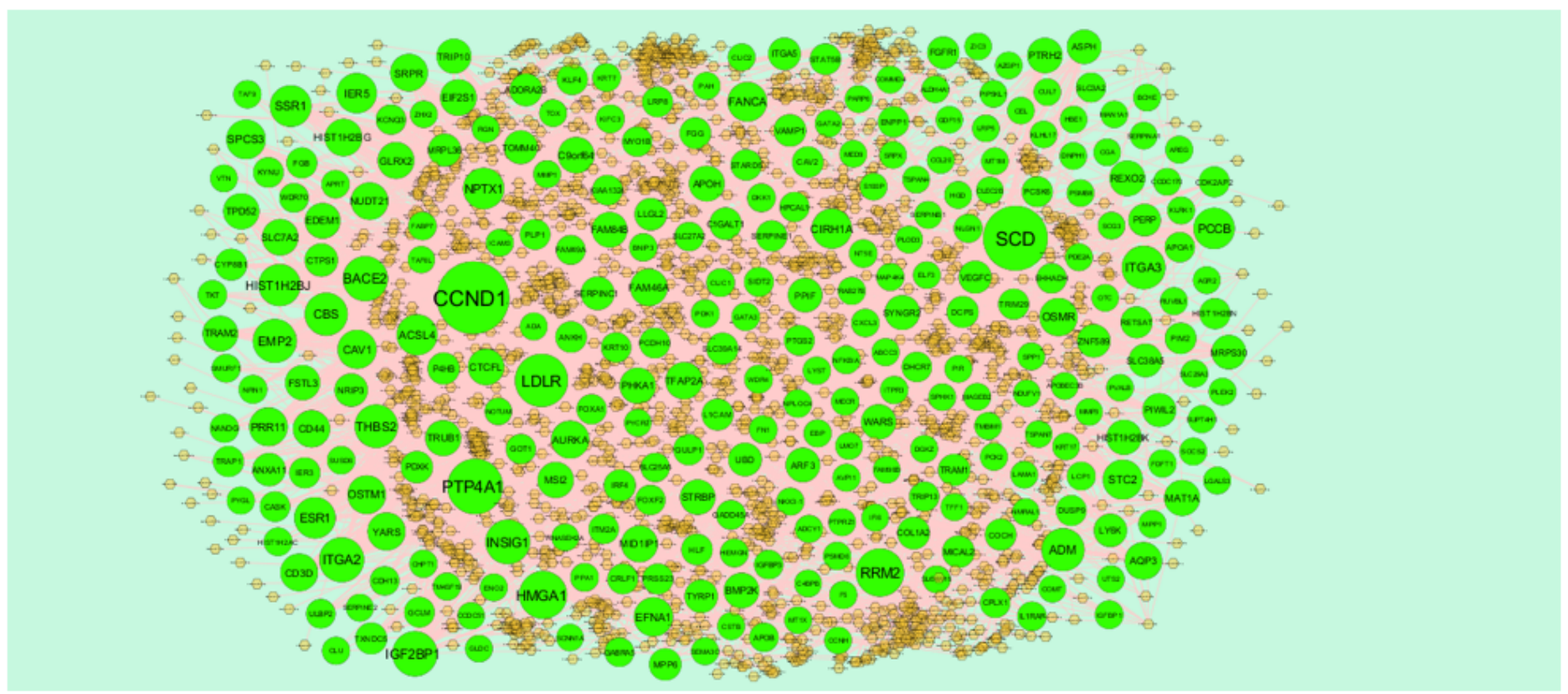

\section{Figure 11}

The network of up regulated genes and their related miRNAs. The green circles nodes are the up regulated genes, and chocolate color diamond nodes are the miRNAs 


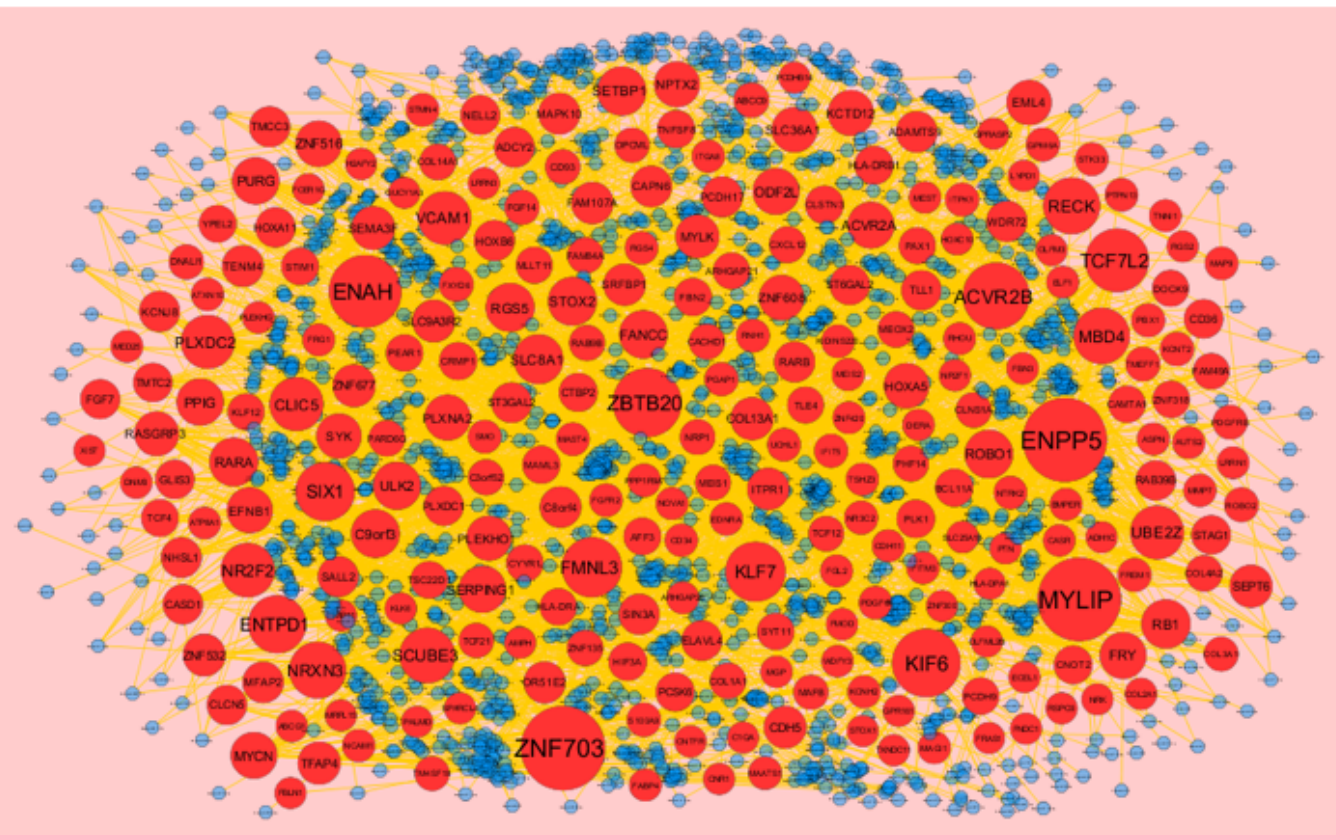

\section{Figure 12}

The network of down regulated genes and their related miRNAs. The red circles nodes are the down regulated genes, and blue color diamond nodes are the miRNAs

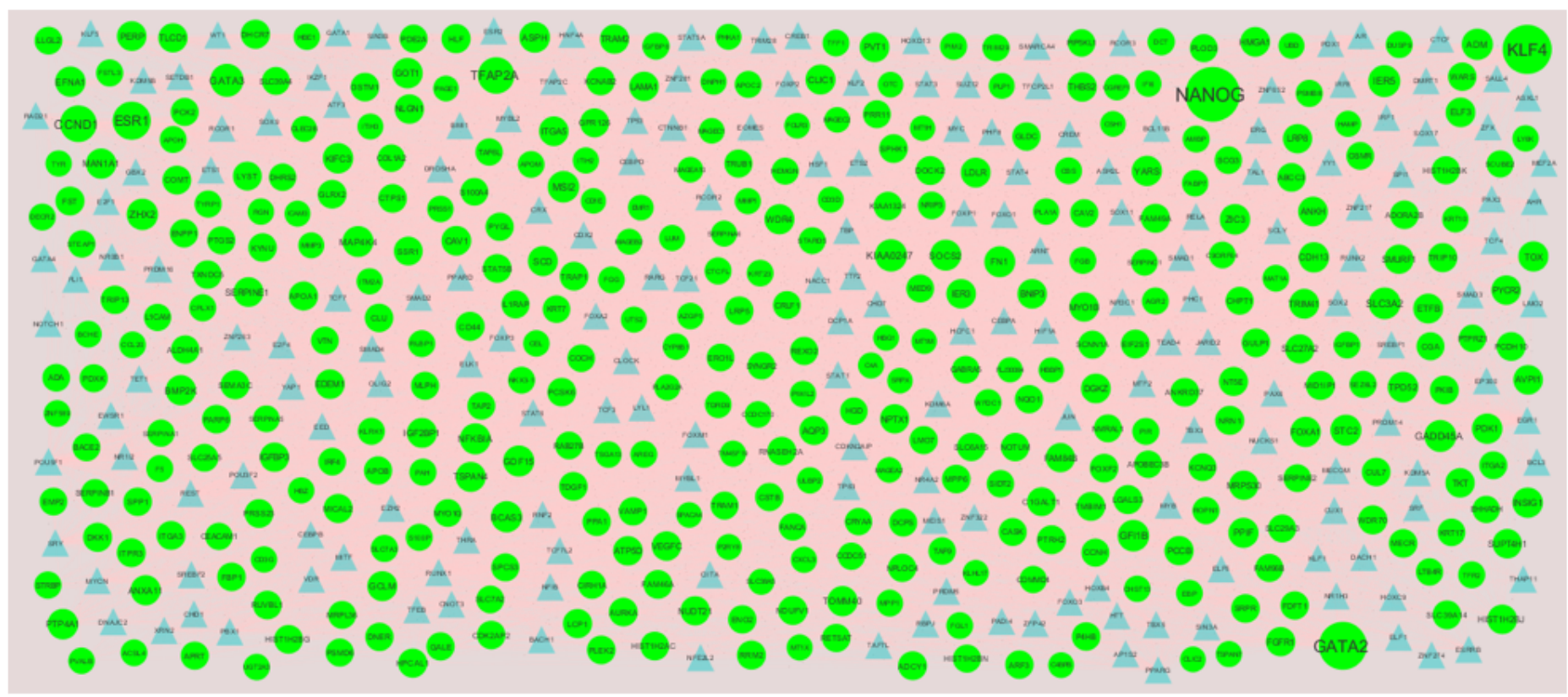

\section{Figure 13}

The network of up regulated genes and their related TFs. The green circles nodes are the up regulated genes, and blue color triangle nodes are the TFs 


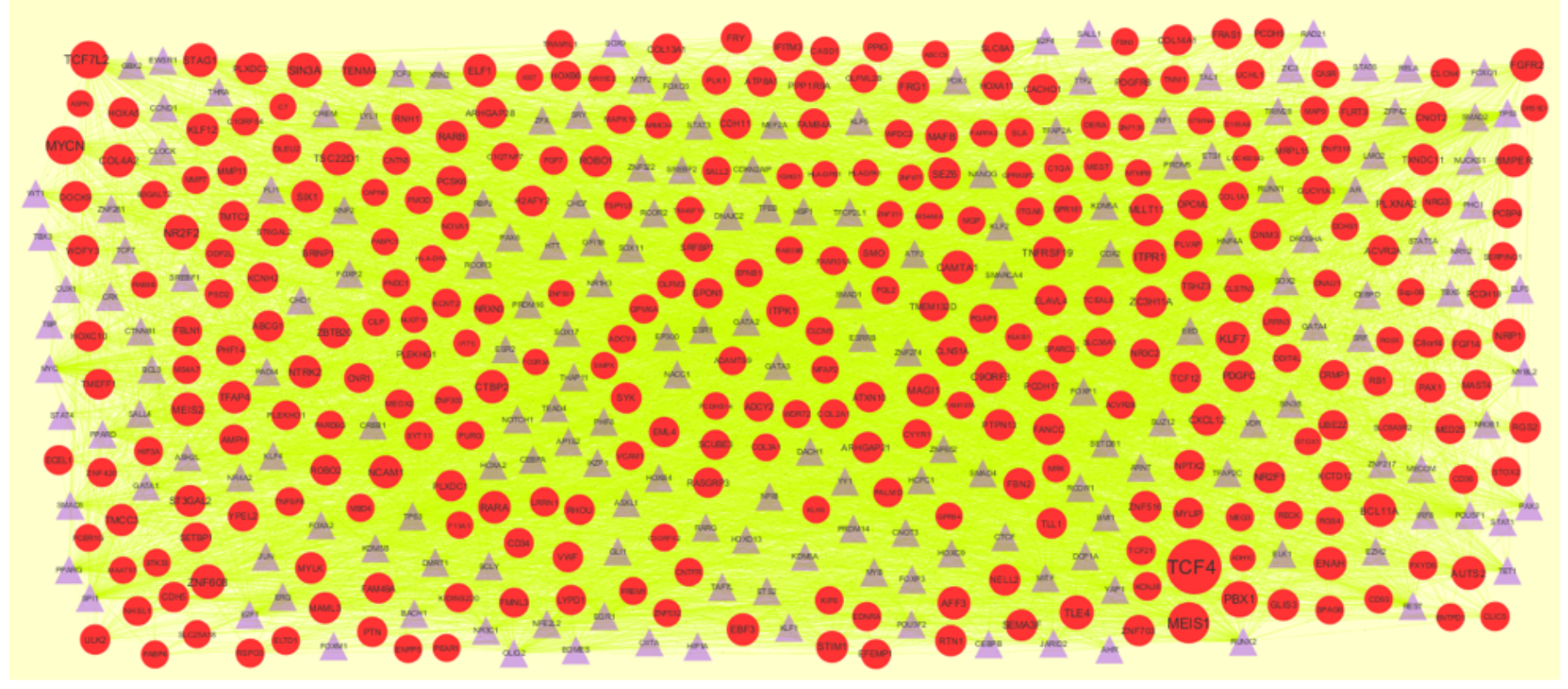

Figure 14

The network of down regulated genes and their related TFs. The green circles nodes are the down regulated genes, and purple color triangle nodes are the TFs
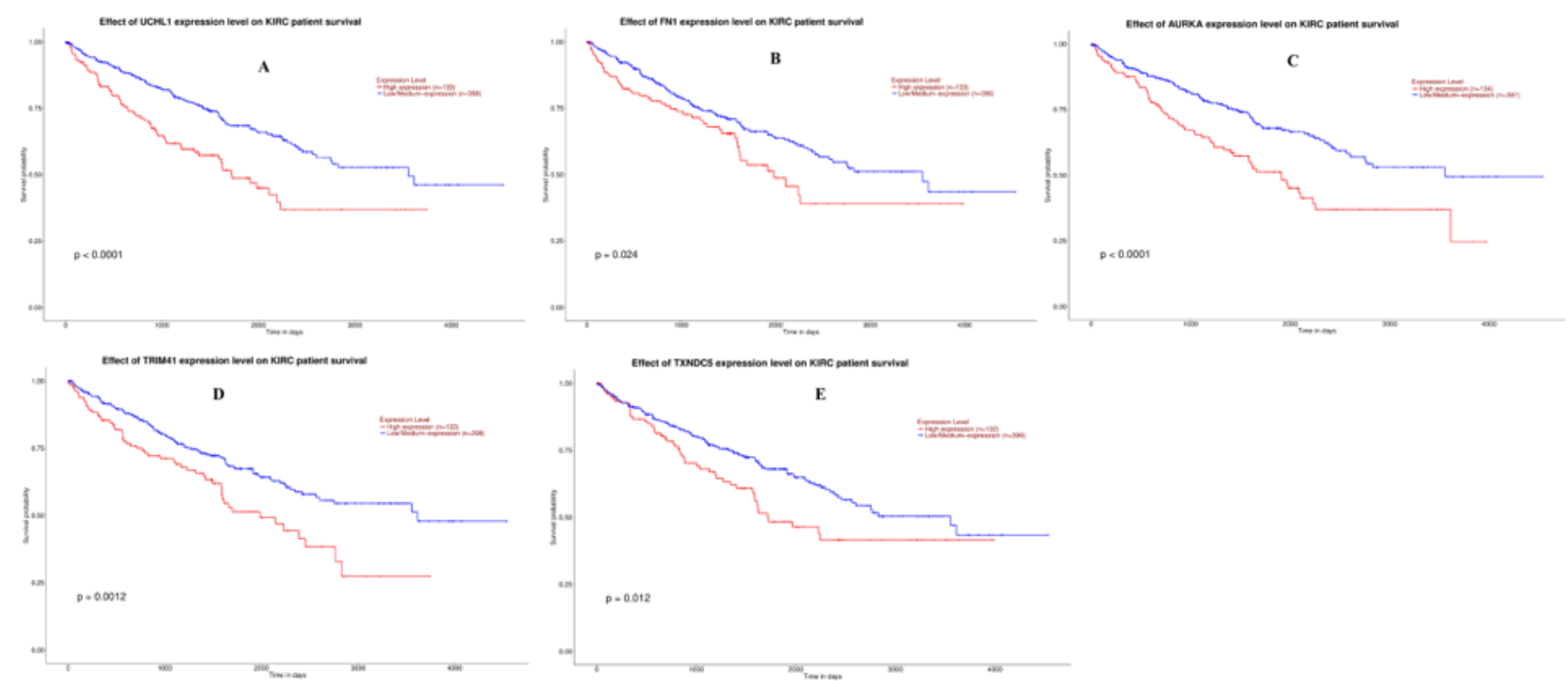

\section{Figure 15}

Overall survival analysis of hub genes. Overall survival analyses were performed using the UALCAN online platform. Red line denotes - high expression; Blue line denotes - low expression A) UCHL1 B) FN1 C) AURKA D) TRIM41 E) TXNDC5 

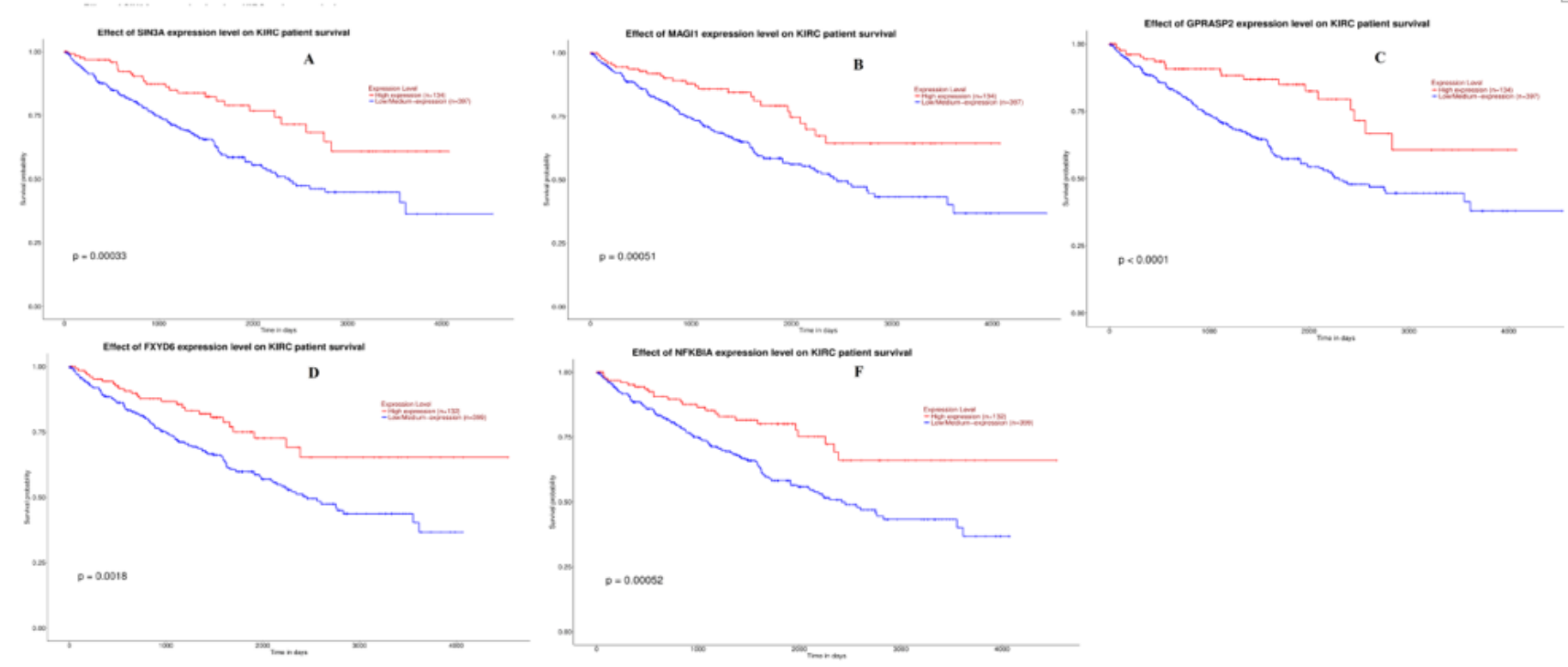

Figure 16

Overall survival analysis of hub genes. Overall survival analyses were performed using the UALCAN online platform. Red line denotes - high expression; Blue line denotes - low expression A) SIN3A B) MAGI1 C) GPRASP2 D) FXYD6 E) NFKBIA
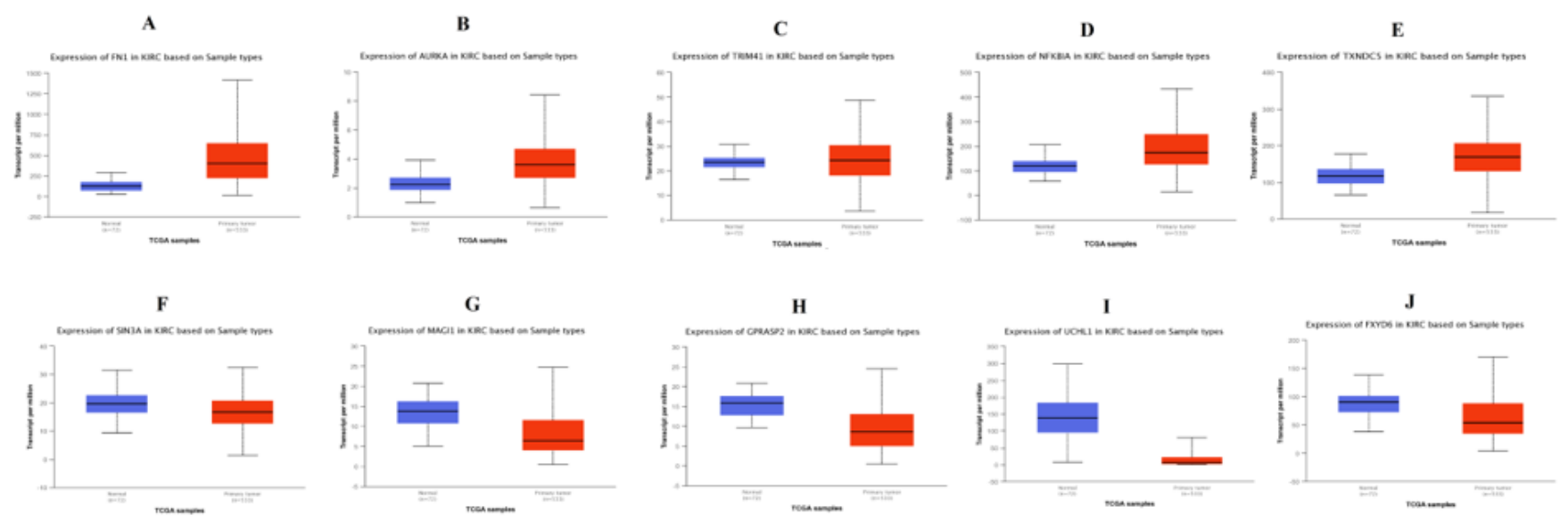

\section{Figure 17}

Box plots (expression analysis) hub genes were produced using the UALCAN platform. A) UCHL1 B) FN1 C) AURKA D) TRIM41 E) TXNDC5 F) SIN3A G) MAGI1 H) GPRASP2 I) FXYD6 J) NFKBIA 


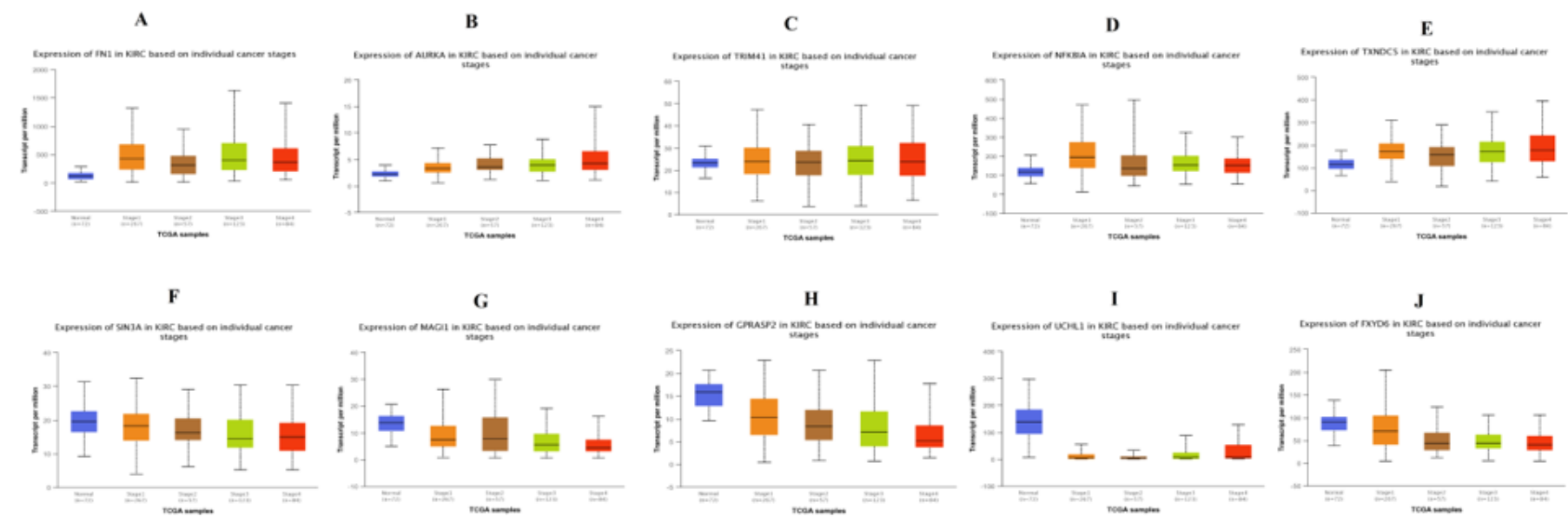

Figure 18

Box plots (stage analysis) of hub genes were produced using the UALCAN platform. A) UCHL1 B) FN1 C) AURKA D) TRIM41 E) TXNDC5 F) SIN3A G) MAGI1 H) GPRASP2 I) FXYD6 J) NFKBIA
A UCHL1 $0 \%$
B $\quad$ FN1 $2 \% \quad|| \mid$
C AURKA $0 \%$

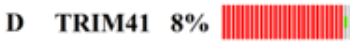
E TXNDC5 $0.6 \%$
$\begin{array}{lll}\text { F } & \operatorname{SIN} 3 \mathrm{~A} & 0.3 \%\end{array}$
G MAGI1 $2.8 \%$ ||||||||
H GPRASP2 2\% ||||||
I FXYD6 $0.3 \%$ |
J NFKBIA $0.3 \%$ |

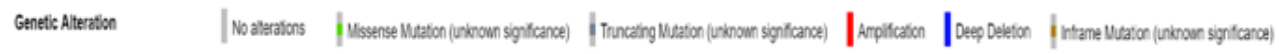

\section{Figure 19}

Mutation analyses of hub genes were produced using the CbioPortal online platform. A) UCHL1 B) FN1 C) AURKA D) TRIM41 E) TXNDC5 F) SIN3A G) MAGI1 H) GPRASP2 I) FXYD6 J) NFKBIA 
A

Normal kideny tissue

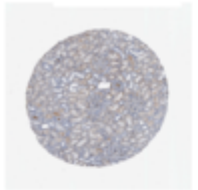

B

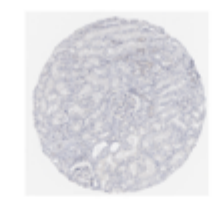

C
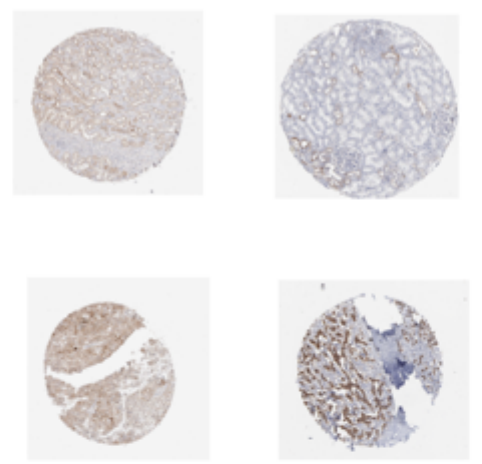

Normal kideny tissue

Wilms tumor tissue
H

F

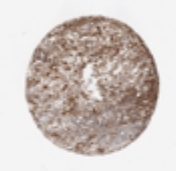

G
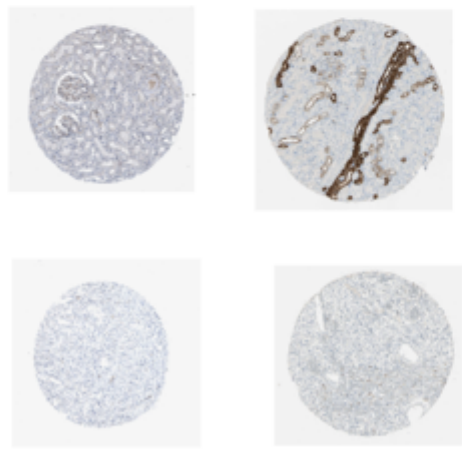

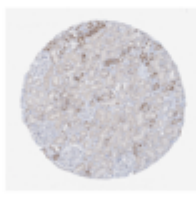

I

E
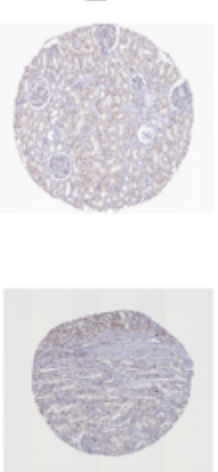

J
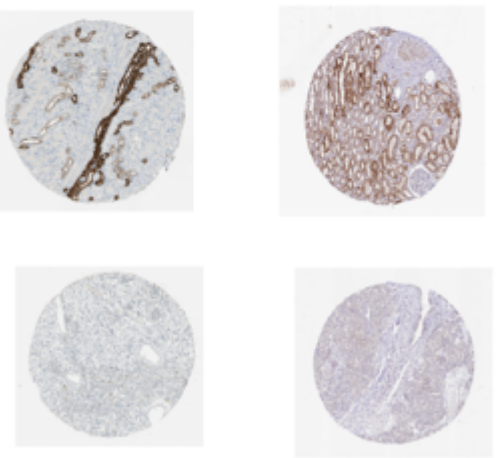

\section{Figure 20}

Immunohisto chemical analyses of hub genes were produced using the human protein atlas (HPA) online platform. A) UCHL1 B) FN1 C) AURKA D) TRIM41 E) TXNDC5 F) SIN3A G) MAGI1 H) GPRASP2 I) FXYD6 J) NFKBIA
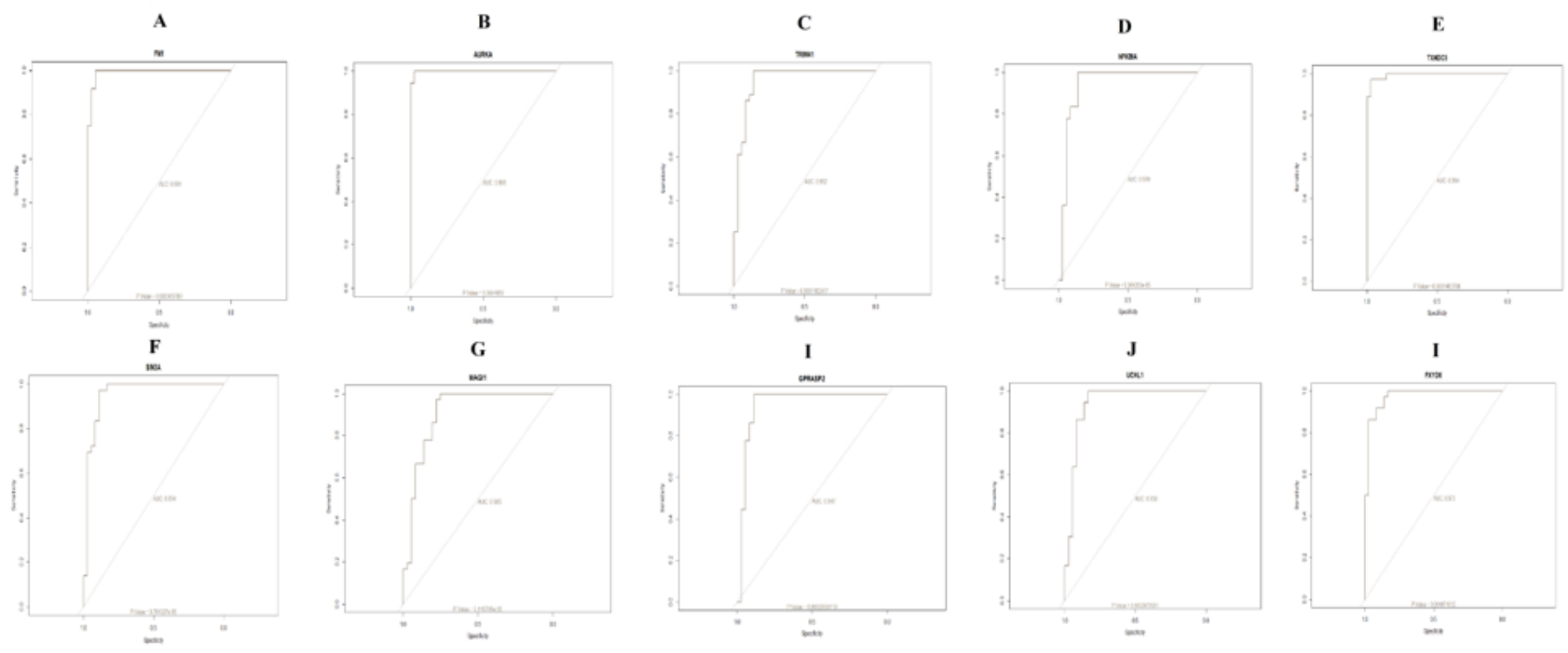

Figure 21 
ROC curve validated the sensitivity, specificity of hub genes as a predictive biomarker for WT prognosis. A) UCHL1 B) FN1 C) AURKA D) TRIM41 E) TXNDC5 F) SIN3A G) MAGI1 H) GPRASP2 I) FXYD6 J) NFKBIA
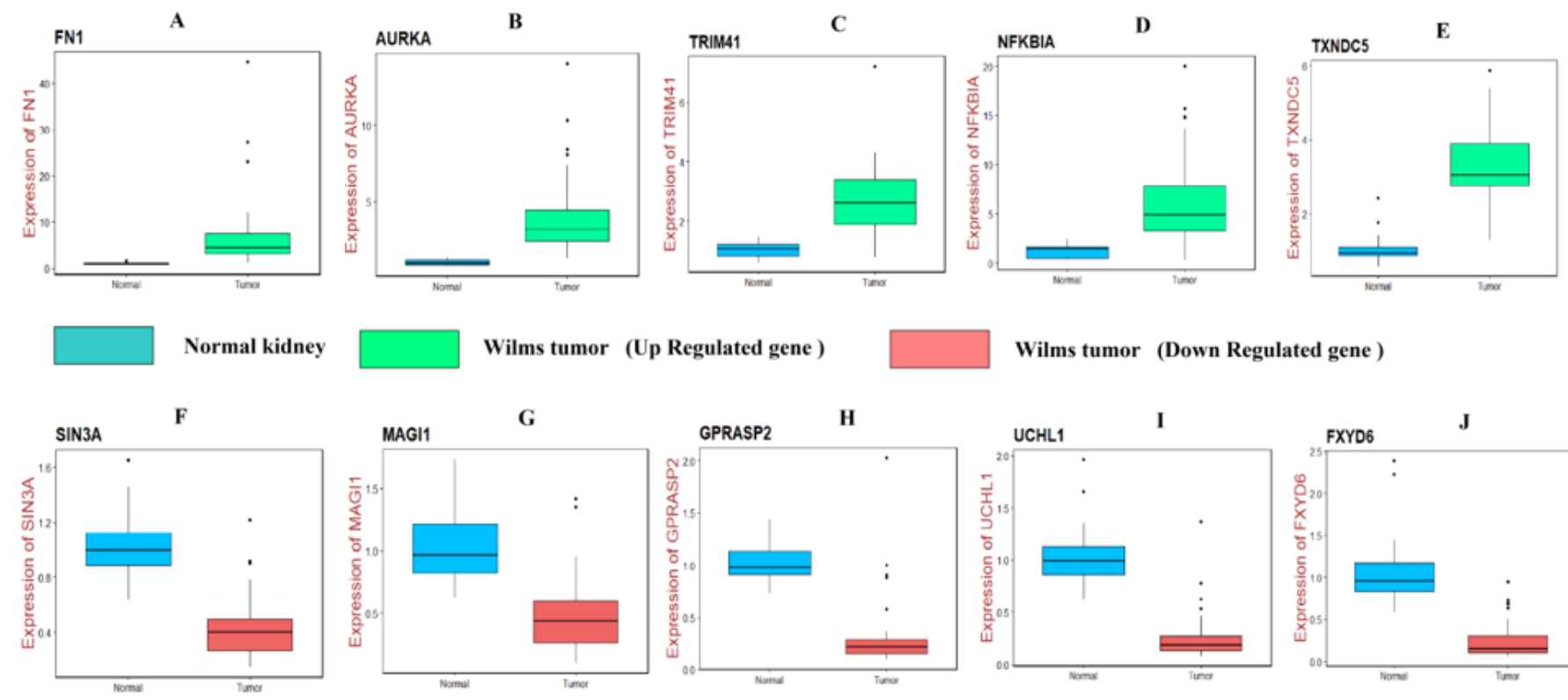

Wilms tumor (Down Regulated gene )
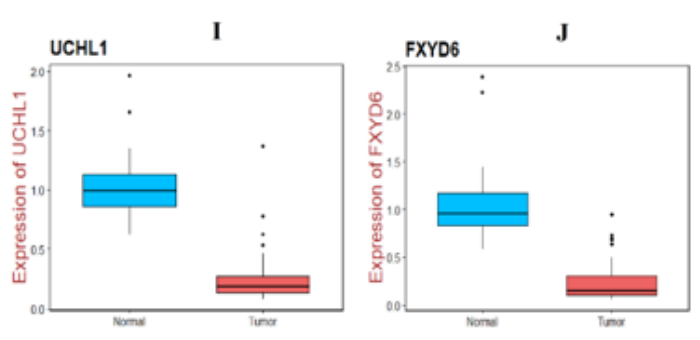

\section{Figure 22}

Validation of hub genes (up and down regulated) by RT- PCR. A) UCHL1 B) FN1 C) AURKA D) TRIM41 E) TXNDC5 F) SIN3A G) MAGI1 H) GPRASP2 I) FXYD6 J) NFKBIA
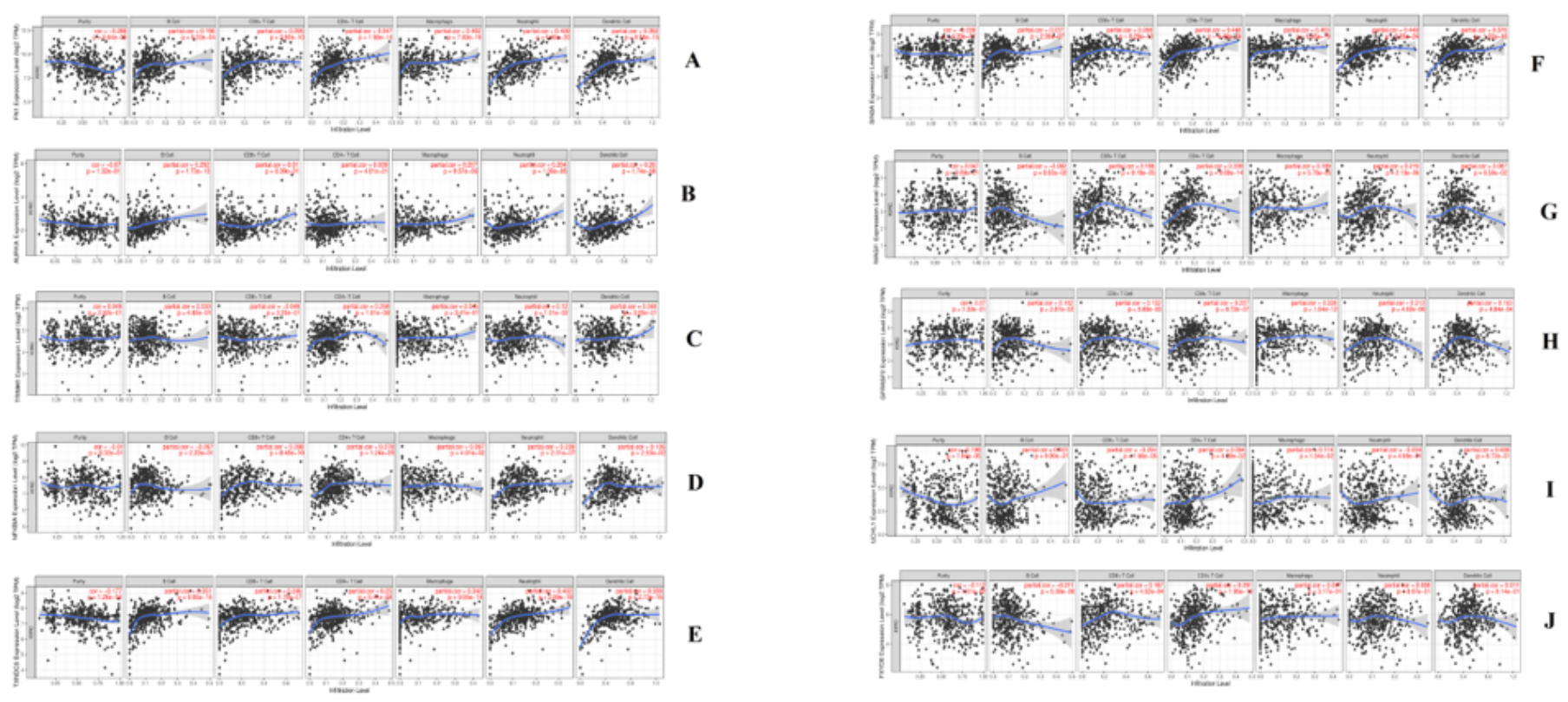

\section{Figure 23}

Scatter plot for immune infiltration for hub genes (up and down regulated). A) UCHL1 B) FN1 C) AURKA D) TRIM41 E) TXNDC5 F) SIN3A G) MAGI1 H) GPRASP2 I) FXYD6 J) NFKBIA 


\section{Supplementary Files}

This is a list of supplementary files associated with this preprint. Click to download.

- Tables.docx 